Article

\title{
Carbon Emission Reduction with Regard to Retailer's Fairness Concern and Subsidies
}

\author{
Linghong Zhang ${ }^{1, *}$, Bowen Xue ${ }^{2}$ and Xiyu Liu ${ }^{2}$ \\ 1 Management Science and Engineering Postdoctoral Mobile Station, Shandong Normal University, \\ Ji'nan 250014, China \\ 2 School of Management Science and Engineering, Shandong Normal University, Ji'nan 250014, China; \\ xbw553759085@126.com (B.X.); sdxyliu@163.com (X.L.) \\ * Correspondence: lhzhang@sdnu.edu.cn; Tel.: +86-053-1861-80509
}

Received: 19 March 2018; Accepted: 12 April 2018; Published: 17 April 2018

check for updates

\begin{abstract}
This paper considers the impact of consumer environmental awareness (CEA), retailer's fairness concern, and government subsidies on the two echelon supply chain with one manufacturer and one retailer. The manufacturer produces green products with carbon emission reduction. The government provides two types of alternative subsidies: a fixed subsidy (referred to as an F-type subsidy) or a discount subsidy (referred to as a D-type subsidy) to encourage the manufacturer to produce a product with a high carbon emission reduction rate. We aim to provide optimal solutions to the manufacturer and the retailer with regard to the retailer's fairness concern and government subsidies; thus we discuss four decision scenarios: the benchmark model without the fairness concern and subsidy, the model with the retailer's fairness concern, the model with fairness concern and the F-type subsidy, and the model with fairness concern and the D-type subsidy. We provide explicit solutions and numerical examples of the optimal carbon emission reduction rate, wholesale price, and retail price. Our study has four main findings: firstly, high consumer environmental awareness will benefit both the manufacturer and the retailer in the above four scenarios; secondly, the fairness concern and subsidy have a counter effect on the optimal strategies (the subsidy could alleviate the negative influence caused by retailer's fairness concern); thirdly, the government could subsidize the retailer when there is unfairness in the supply chain so that the manufacturer could produce a product with lower carbon emission; finally, using the subsidy related to the environmental quality will be more helpful for improving environment quality, especially when the government has a budget constraint.
\end{abstract}

Keywords: carbon emission reduction rate; fairness concern; consumer environmental awareness; government subsidy

\section{Introduction}

As environment quality decreases, consumer environmental awareness increases and more and more consumers are willing to purchase environment-friendly products [1,2]. Hence, some manufacturers begin to produce the product with low carbon emission levels. In 1997, Chevrolet began to market its S-10 electric pickup truck, which was considered much more environmentally friendly than other models using conventional combustion engines and fuels [3]. However, its lower carbon emissions resulted in a higher price because of its green technology immaturity. For example, the pure electric vehicle has a higher carbon emission reduction rate than that of the hybrid electric vehicle, and always has a higher price than that of the hybrid electric vehicle with similar traditional functions. Therefore, the manufacturer needs to determine which type of green product (with high or low carbon emission levels) to produce to cater to the increment of the green product's demand. Note that in 
this paper we focus on green products that generate lower carbon emission, not the green production technology used in the process of the production.

For green products with environmental externalities, the government always implements a subsidy to maximize social welfare [4,5]. Government subsidies impact the supplier's production and pricing decisions [6]. However, not all the subsidies are efficient. Diamond (2009) concluded that there is a much weaker relationship between incentive policies and hybrid adoption, and even a strong relationship between gasoline price and hybrid adoption [7]. Lobel and Perakis (2011) stated that the current policies in Germany for the adoption of solar photovoltaic technology are not efficient [8]. Hence, for the government it is very important to adopt a proper subsidy strategy. In this paper, we will compare the effectiveness of the two types of subsidies and make suggestions to the government.

In addition, in the supply chain the fairness concern is also a new factor that needs to be considered, especially with regard to the government subsidy. The manufacturer and the retailer in a two echelon supply chain are comparable in terms of status, income, and other aspects, which is defined as distributional fairness concern [9-11]. In this paper, we will mainly discuss the distributional fairness concern, and denote it as fairness concern briefly. Under decentralized decisions, supply chain members pay great attention to fairness, which often intensifies the double marginalization and reduces the utility of the supply chain [12]. When receiving a government subsidy, the manufacturer or the retailer may thereby obtain much more profit, which often displeases the other party in the supply chain. Hence, the government needs to consider both the fairness concern and CEA to set proper subsidies. Therefore, in this paper we will consider the CEA, fairness concern, and government subsidies simultaneously, and mainly investigate the following questions:

1. How has the carbon emission reduction rate of green products changed with regard to the subsidy and fairness concern?

2. How has the government subsidy types (fixed subsidy and discount subsidy) affected the manufacturer's and retailer's strategies?

3. How has the fairness concern affected the manufacturer's and retailer's profits when there is a government subsidy?

Our study contributes to the literature in following two ways: (1) We introduce the fairness concern in the supply chain when the manufacturer produces the green product. Most studies that focus on green products do not consider the fairness concern $[4,5,13]$; $(2)$ We explore the changes of the optimal carbon emission reduction rate and both parties' profits with the fairness concern and government subsidy. Qiu (2013) analyzed the effects of government subsidies and the fairness concern on the decision making and performance of the two parties, but this paper does not discuss the change in the carbon emission reduction rate of green products [14].

Therefore, the impacts of CEA, the fairness concern, and the government subsidy on optimal decisions and profits in the two-echelon supply chain under the low carbon background will be significant. This paper aims to provide optimal solutions for the manufacturer and the retailer when retailer's fairness concerns and a government subsidy are present, and further present the change trends of the optimal solutions with the CEA, retailer's fairness concern, and subsidies, finally make some suggestions for manufacturers, retailers, and the government.

The reminder of this paper is organized as follows. Section 2 provides a review of relevant literature. Section 3 shows the model description and the benchmark model, and Section 4 presents the three extended models and compares results obtained from the four models. Section 5 gives some numerical examples to illustrate our results more intuitively. Section 6 summarizes the conclusions and discusses limitations and future research. All proofs are relegated to Appendix A.

\section{Literature Review}

Based on the topic we discussed, our work is related to following two aspects. One aspect is the study about green products from the perspective of the CEA and government policies; another aspect 
is the study about the fairness concern in supply chain. Therefore, we will summarize the literature from above two aspects.

\subsection{CEA and Government Policies}

There are two main reasons for the increment demand for green products: one is the increasing CEA, and the other is subsidy offered by government. Thus, we present the literature in following two streams: first, we give the papers combining the green product and CEA. Amacher et al. (2004) studied how duopoly manufacturers determined the green technology investment, environmental quality, and price competition with different consumer preferences [15]. Liu et al. (2012) considered CEA and manufacturer competition between partially substitutable products to show the optimal product design and price in a duopoly [16]. Zhang et al. (2015) discussed the impact of CEA on green products' order quantities and channel coordination within a one-manufacturer and one-retailer supply chain [2]. $\mathrm{Xu}$ and Wang (2018) explored the decision strategy and profit distribution of a closed-loop supply chain with retail price and emission reduction-dependent demand when consumers have different preferences regarding new and remanufactured products [17].

Because of the externalities of green products, government always subsidizes green products or environmental consumers who purchases green products, especially when CEA is quite low; hence, there are some papers that call the government policy into consideration. Bansal and Gangopadhyay (2003) investigated the problem from the perspective of the policy maker, aiming to find the optimal subsidy to maximize social welfare in the presence of environmentally aware consumers [18]. Zhang et al. (2012) investigated the interactions among customers' preferences, firms' product strategies, and government subsidy policies from the perspective of the new product design [4]. Yu et al. (2016) studied how oligopolistic manufacturers provide different products with distinct green levels to satisfy consumer demands with regard to different green preferences [19]. Cohen et al. (2016) considered a newsvendor setting in which the supplier adjusts its production and price depending on the level of subsidies to maximize his profit, and the government aims to use smallest subsidy [6]. Liu et al. (2017) discussed how the subsidies stimulate the combined heat power plants to employ electric boilers to relieve the wind power curtailment problem in regional power grids during the winter heating season [20]. Zheng et al.(2018) explored the limitations of Chinese electric vehicle market and analyzed the impact of subsidies on the optimal production and pricing decisions of an auto manufacturer [21].

There are also some other policies such as tax, carbon cap-and-trade schemes, emission regulations, and so on. In recent years, European Union Emissions Trading Scheme (EU ETS), as the most effective way to regulate and reduce carbon emission, has received much more attention. Oestreich and Tsiakas (2015) made an empirical study on the influence of EU ETS on German stock returns and found that in the first few years of the program, companies that received an average free carbon emission quota were significantly better than those without [22]. Martin et al. (2016) summarized the results of original research papers on emissions, economic performance and competitiveness, and innovation, and concluded by highlighting gaps in the current literature and suggesting priorities for future research on this landmark policy [23].

In the process of emission reduction, the manufacturer may cost more when adopting relevant carbon emission reduction technologies [24] and obtain much more profit than that of the retailer; thus, the retailer may feel hard done by. Therefore, much research has focused on fairness among supply chain members.

\subsection{Supply Chain and Fairness Concern}

The supply chain literature mainly focuses on analyzing supplier-retailer contracts and channel coordination to reduce the profit loss of the whole supply chain because of double marginalization. Most of literature assumes that the decision makers are completely rational and seek to maximize their profits, such as $[25,26]$; however, members are very concerned about the profit allocation between 
supply chain's members [27]. Therefore, there are some papers that consider the problem of channel coordination and the fairness concern simultaneously. Our paper is related to following papers.

Cui et al. (2007) demonstrated that the manufacturer can use a simple wholesale price above their marginal cost to coordinate this channel to maximize channel profit and channel utility when channel members are concerned about fairness [28]. Demirag et al. (2010) extended Cui et al [28]'s results and revealed that the exponential demand function requires less stringent conditions to achieve coordination when only the retailer is fairness-concerned [29]. Du et al. (2014) investigated news-vendor problem for a dyadic supply chain in which both the supplier and the retailer care about fairness [30]. Du et al. (2010) discussed how the retailer's behavior of fairness concern influences the coordination of supply chain, including the wholesale-price contract, the buyback contract, and the revenue-sharing contract [12]. Chen et al. (2015) studied a supply chain in which a manufacturer designs a contract to a potential backup supplier to mitigate the yield uncertainty of the primary supplier. The backup supplier may compare with the primary supplier and have horizontal fairness concern [31]. Li and $\mathrm{Li}$ (2016) studied dual-channel (the manufacturer added a direct channel) supply chain equilibrium problems regarding retail services and fairness concern [32]. Jiang et al. (2017) explored the initial allocation of carbon emission permits among the provinces of China from the perspective of fairness and constructed a model of the initial inter-provincial allocation of carbon emission permits [33]. Nie and $\mathrm{Du}$ (2017) investigated quantity discount contracts in a dyadic supply chain that consists of one supplier and two retailers [11]. They considered peer-induced fairness concern and distributional fairness concern simultaneously.

However, most literature above did not consider a scenario in which the manufacturer produces green products in the supply chain and the government implements subsidies to the consumer simultaneously.

Therefore, in this paper we will study the impact of government subsidies and fairness concern at the same time on the manufacturer's and retailer's strategies. Furthermore, most of the studies based on government subsidies have only considered a single subsidy type; in this paper, we will discuss two types subsidies: the fixed subsidy and discount subsidy, and we will compare the effectiveness of these two subsidies.

Based on above two aspects of papers, we summarize the papers that are most related to our paper in Table 1. We denote the carbon emission reduction rate as the environmental quality of the green product, because different papers may consider different environmental qualities of the green product (such as the recycling of production materials), but their models are similar. CEA, subsidy and fairness concern are the important factors in our paper; then, we add them into our classification criteria, and the coordination contract is a significant research issue in the supply chain, as well as a criterion.

Table 1. Papers that are most related to our research.

\begin{tabular}{cccccc}
\hline Author & CEA & $\begin{array}{c}\text { Product's Environmental } \\
\text { Quality }\end{array}$ & $\begin{array}{c}\text { Supply Chain } \\
\text { Coordination Contract }\end{array}$ & Subsidy & $\begin{array}{c}\text { Fairness } \\
\text { Concern }\end{array}$ \\
\hline Zhang et al. (2015) [2] & $\sqrt{ }$ & $\sqrt{ }$ & $\sqrt{ }$ & \\
Zhou and Huang (2016) [13] & $\sqrt{ }$ & $\sqrt{ }$ & & $\sqrt{ }$ \\
Sun and Xiao(2017) [26] & $\sqrt{ }$ & & & $\sqrt{ }$ & \\
Cheng et al. (2015) [34] & & $\sqrt{ }$ & $\sqrt{ }$ & $\sqrt{ }$ \\
Zhao and Lin (2017) [35] & & & $\sqrt{ }$ \\
Qiu (2013) [14] & & $\sqrt{ }$ & & $\sqrt{ }$ \\
Du et al. (2010) [12] & $\sqrt{ }$ & $\sqrt{ }$ & & $\sqrt{ }$ \\
This paper & & & & \\
\hline
\end{tabular}

\section{Problem Assumptions and Benchmark Model}

\subsection{Problem Assumptions}

We assume that there is one manufacturer and one retailer in a two echelon supply chain, and the green product is provided in the supply chain. Compared with non-green products, green products 
have environmental quality (i.e., low carbon emission levels per $100 \mathrm{~km}$ ). We consider the impact of consumer environmental awareness and carbon emission reduction rate of the green products on market demand. Market demand increases with CEA and carbon emission reduction rate of green products $[2,16]$, and decreases with the retail price. We consider that the demand function for green products denoted by $D$ possesses the following structure:

$$
D=a-b p+\tau e(a>0, b>0)
$$

in which $a$ is the basic demand of products, $b$ is the sensitivity towards retail price, $p$ is the retail price of unit product, $\tau$ represents CEA [2], and $e$ is the carbon emission reduction rate of green products, which is defined as the decreased amount of carbon emission of green products per 100 kilometers divided by the amount of non-green products' carbon emission per $100 \mathrm{~km}$. Here, we assume that $a-b p>0$. As suggested in prior studies, CEA affects consumer's willingness-to-pay $[1,2]$ and the demand of the green products; the higher CEA, the higher demand of green products. CEA can vary greatly across industries and consumer groups and can change over time [36,37]. In our model, we focus on the impact of the CEA on the carbon emission reduction rate; thus, we assume CEA is a constant and will analyze the change of the CEA on the optimal solutions in Sections 3-5.

Similar to Zhu and He (2017) [38], we model the R\&D cost for carbon emission reduction rate $e$ as an increasing quadratic function as $c_{e} e^{2}$, independent of the production volume, and $c_{e}$ is a strictly positive cost coefficient. We summarize the major parameters and decision variables we will use in model development in Table 2.

Table 2. Model parameters and decision variables.

\begin{tabular}{cl}
\hline Parameters & The Meanings of the Parameters \\
\hline$a$ & Basic demand of the green product \\
$b$ & The demand sensitivity coefficient to price \\
$\tau$ & Consumer environmental awareness \\
$\lambda$ & Retailer's equity concern coefficient \\
$s$ & Subsidy for one unit product in F-type \\
$\beta$ & Subsidy coefficient in D-type \\
$c_{e}$ & The cost coefficient of the environmental quality \\
$\pi r, \pi m$ & Retailer's profit and manufacturer's profit \\
$U \pi r$ & Utility of the retailer \\
$U \pi_{m}$ & Utility of the the manufacturer \\
\hline Decision variables & The Meanings of the Decision Variables \\
\hline$e i$ & Carbon emission reduction rate per unit of green product \\
$w$ & Wholesale price of unit product \\
$p$ & Retail price of unit product \\
\hline
\end{tabular}

Then, the retailer's profit function and the manufacturer's profit function are as follows:

$$
\begin{gathered}
\pi r=(p-w) D=(p-w)(a-b p+\tau e) \\
\pi m=w D-\frac{c_{e} e^{2}}{2}=w(a-b p+\tau e)-\frac{c_{e} e^{2}}{2}
\end{gathered}
$$

\subsection{Benchmark Model}

The supply chain members maximize their utility functions by setting the optimal wholesale price, the carbon emission reduction rate, and the retail price with CEA. In this subsection, we assume that neither the retailer nor the manufacturer is concerned about the fairness; then, the manufacturer's and retailer's utility functions are considered their profit functions. Assume that the manufacturer is the leader and the retailer is the follower: firstly, the manufacturer determines the carbon emission 
reduction rate and the wholesale price of the green product; then, the retailer determines the retail price of the green product to maximize his own utility.

Similar to [2,16], we apply the backward method to solve above Stackelberg game problem, and in following sections we also use this method to obtain optimal solutions. The specific procedures of the backward method are as follows: first, we solve the retailer's utility function to obtain the optimal retail price under the condition that the carbon emission reduction rate and the wholesale price are given; then, we solve the manufacturer's utility function to obtain the optimal emission reduction rate and wholesale price after the retail price is derived.

Assumption 1. Consumer environmental awareness satisfies $\tau<2 \sqrt{b c_{e}}$.

Assumption 1 is that it is impossible for CEA to be infinitely large, and it has a boundary. The boundary is determined by the cost coefficient and the demand sensitivity coefficient to price.

Theorem 1. The optimal carbon emission reduction rate of the green product is

$$
e_{1}=\frac{a \tau}{4 b c_{e}-\tau^{2}}
$$

Theorem 2. The optimal wholesale price and retail price are as follows:

$$
\begin{aligned}
& w 1=\frac{2 a c e}{4 b c_{e}-\tau^{2}} \\
& p 1=\frac{3 a c e}{4 b c e-\tau^{2}}
\end{aligned}
$$

Theorems 1 and 2 present the optimal carbon emission reduction rate; the wholesale price and price are determined by the CEA, the cost coefficient, and demand.

Proposition 1. The optimal carbon emission reduction rate of green products increases with $\tau$.

Proposition 2. The optimal wholesale price, optimal retail price, the manufacturer's profit, the retailer's profit, and the total supply chain profit increase with $\tau$.

From Propositions 1 and 2, we obtain that high CEA could benefit both the manufacturer and the retailer. Therefore, the supply chain members could invest more on improving CEA together.

\section{Retailer's Fairness Concern and Government Subsidy}

In this section, we first introduce the scenario in which the retailer is concerned about fairness but the manufacturer does not care about the fairness. Regarding the retailer's fairness concern, we consider the effect of government subsidies on manufacturer's and retailer's strategies. Especially, we consider that there are two types of subsidies for the consumer [13]: fixed subsidy and discount subsidy for unit product. Finally, we compare the optimal carbon emission reduction rate, wholesale price, and retail price in above different scenarios, and analyze the influence of fairness concern, CEA, and government subsidies on the manufacturer's, retailer's, and the whole supply chain's profits.

\subsection{Fairness Concern}

In this subsection, we consider that the retailer is concerned about fairness but the manufacturer does not care about fairness; in other words, the retailer maximizes her utility depending on the profits 
of both members. Similar to Du et al. (2010) [12], we capture the fairness in the retailer's objective function through the following utility function:

$$
U \pi r=\pi r-\lambda(\pi m-\pi r)=(1+\lambda) \pi r-\lambda \pi m
$$

in which $\lambda(0<\lambda<1)$ represents the retailer's fairness concern coefficient.

The manufacturer's utility function is still the profit function, because the manufacturer is not concerned about fairness. Then, the manufacturer's utility function is as follows:

$$
U \pi m=\pi m=w(a-b p+\tau e)-\frac{c_{e} e^{2}}{2}
$$

From Equation (8), we can see that the retailer's utility function is determined by his profit and the profit difference between the manufacturer and the retailer. If the manufacturer makes much more money than that of the retailer in the supply chain, the retailer's utility will be lower, even if he has earned much less money. Additionally, the larger the retailer's fairness concern, the higher the retailer's utility.

Similar to Section 3.2, we assume the manufacturer is the leader and the retailer is the follower; then, we derive optimal solutions using the backward method.

Theorem 3. The optimal carbon emission reduction rate is

$$
e_{2}=\frac{(\lambda+1) a \tau}{4 b c_{e}(2 \lambda+1)-\tau^{2}(\lambda+1)}
$$

Compared with Theorem 1, the optimal carbon emission reduction rate decreases when the retailer cares about fairness; in other words, retailer's fairness concern will result in decreasing environmental quality of the green products.

Theorem 4. When the retailer is concern about fairness, then the optimal wholesale price and the optimal retail price are as follows:

$$
\begin{aligned}
& w_{2}=\frac{2 a c e(\lambda+1)}{4 b c e(2 \lambda+1)-\tau^{2}(\lambda+1)} \\
& p_{2}=\frac{3 a c e(2 \lambda+1)}{4 b c e(2 \lambda+1)-\tau^{2}(\lambda+1)}
\end{aligned}
$$

Above, Theorems 3 and 4 present the optimal strategies when the retailer cares about fairness. Let $\lambda=0$; this means the retailer is not concern about fairness, and the Formulas (9)-(11) are same as Formulas (4)-(6).

Proposition 3. When the retailer is concerned about fairness, then the optimal wholesale price, retail price, manufacturer's profit, retailer's profit, retailer's utility, and supply chain's utility increase with CEA.

From Proposition 3, we can see that the change trends of the optimal solutions with CEA when the retailer is concerned about the fairness are the same as those without fairness;

Proposition 4. When the retailer cares about fairness, then the manufacturer's optimal carbon emission reduction rate of green products' optimal wholesale price and retail price decrease with $\lambda$.

Proposition 4 shows that the retailer's fairness concern decreases the optimal strategies of both the manufacturer and the retailer, especially the carbon emission reduction rate. Therefore, when 
the retailer cares about the fairness, the manufacturer will lower carbon emission reduction rate. This is not good news for the public, because the lower carbon emission reduction rate, the lower environment quality. Next, we will discuss the profit change with regard to the fairness concern.

Proposition 5. When the retailer cares about fairness, then

(i) When $\lambda<\frac{4 b c_{e}-2 \tau^{2}}{5 \tau^{2}-8 b c_{e}}$, then the retailer's profit increases with $\lambda$; and when $\frac{4 b c_{e}-2 \tau^{2}}{5 \tau^{2}-8 b c_{e}}<\lambda<\frac{4 b c_{e}-\tau^{2}}{\tau^{2}-8 b c_{e}}$, then the retailer's profit decreases with $\lambda$;

(ii) The optimal manufacturer's profit decreases with $\lambda$.

When the retailer cares about fairness, Proposition 5 shows that the manufacturer's profit decreases all the time; the retailer's profit only increases in a certain zone. Once the level of the fairness concern exceeds a certain zone, the retailer's profit decreases. In other words, the retailer's profit first increases then decreases with $\lambda$.

Propositions 4 and 5 show that when the retailer cares about fairness, the retailer will remove the unfairness and increase his profit and utility in a certain zone. However, when the retailer pays excessive attention to fairness, both manufacturer's and retailer's profits decrease; in other words, the retailer's behavior makes both members suffer loss, and the retailer not only cannot remove unfairness but also makes own their situation worse.

\subsection{Fairness Concern and Government Subsidy}

With retailer's fairness concern, in this subsection, we will discuss the effects of two government subsidies on the supply chain. Here we will consider two types subsidy: F-type subsidy (in which the consumer obtains a fixed subsidy $s$ when the consumer purchases one unit product) and D-type subsidy (in which the consumer obtains a discount subsidy that is related to the green level of the product when the consumer purchases one unit product). Firstly, we will discuss how the F-type subsidy impacts the optimal solutions such as the optimal wholesale price, retail price, each party's profit, and so on. Then, we will discuss how the D-type subsidy affects supply chain members' strategies. Finally, we'll compare the optimal solutions with two subsidies and give the differences between them.

\subsubsection{F-Type Subsidy}

Assume that the government provides fixed unit product subsidy $s$ to the consumer when the consumer purchases green products. Then, the demand function is as follows:

$$
D=a-b(p-s)+\tau e
$$

Then, the retailer's and manufacturer's profit functions are as follows:

$$
\begin{gathered}
\pi_{r 3}=(p-w) D=(p-w)[a-b(p-s)+\tau e] \\
\pi_{m 3}=w D-\frac{c_{e} e^{2}}{2}=w[a-b(p-s)+\tau e]-\frac{c_{e} e^{2}}{2}
\end{gathered}
$$

Similar to Section 4.1, the retailer's utility function with fairness concern is

$$
U \pi_{r}=\pi_{r}-\lambda\left(\pi_{m}-\pi_{r}\right)=(1+\lambda) \pi_{r}-\lambda \pi_{m} .
$$

The manufacturer's utility function is as follows:

$$
U \pi_{m}=\pi_{m}=w[a-b(p-s)+\tau e]-\frac{c_{e} e^{2}}{2}
$$


Theorem 5. With F-type subsidy and retailer's fairness concern, the optimal carbon emission reduction rate of the green product is

$$
e_{3}=\frac{\tau(\lambda+1)(a+b s)}{4 b c_{e}(2 \lambda+1)-\tau^{2}(\lambda+1)}
$$

Compared with Theorem 3, we can obtain that the optimal carbon emission reduction rate increases when it is subsidized.

Theorem 6. With F-type subsidy and retailer's fairness concern, the optimal wholesale price and retail price are as follows:

$$
\begin{aligned}
w_{3} & =\frac{2 c_{e}(a+b s)(\lambda+1)}{4 b c_{e}(2 \lambda+1)-\tau^{2}(\lambda+1)} \\
p_{3} & =\frac{3 c_{e}(2 \lambda+1)(a+b s)}{4 b c_{e}(2 \lambda+1)-\tau^{2}(\lambda+1)}
\end{aligned}
$$

Theorems 5 and 6 present the changes of optimal carbon emission reduction rate, the wholesale price and price with CEA, the fairness concern, and F-type subsidy.

\section{Proposition 6.}

(i) The optimal carbon emission reduction rate of the green product, wholesale price, and retail price increase with CEA;

(ii) The manufacturer's and retailer's profits increase with CEA.

Proposition 6 gives the change trends with CEA; the results are similar to Proposition 3, so the introduction of government subsidies does not influence the effects of CEA on each party's strategies.

\section{Proposition 7.}

(i) The optimal carbon emission reduction rate, optimal wholesale price, and retail price decrease with $\lambda$;

(ii) The manufacturer's profit decreases with $\lambda$;

(iii) the retailer's profit increases with $\lambda$ when $\lambda<\frac{4 b c_{e}-2 \tau^{2}}{5 \tau^{2}-8 b c_{e}}$ and decreases when $\frac{4 b c_{e}-2 \tau^{2}}{5 \tau^{2}-8 b c_{e}}<\lambda<\frac{4 b c_{e}-\tau^{2}}{\tau^{2}-8 b c_{e}}$.

Notice that Propositions 5 and 7 have same results even there is F-type subsidy in Proposition 7. In other words, the F-type subsidy and the retailer's fairness concern do not interact with each other.

\section{Proposition 8.}

(i) The optimal carbon emission reduction rate, wholesale price, and retail price increase with the fixed subsidy s;

(ii) The manufacturer's and retailer's profits increase with the fixed subsidy s.

Proposition 8 shows the impact of government subsidies on the optimal carbon emission reduction rate, wholesale price, retail price, and manufacturer's and retailer's profits. Obviously, the fixed subsidy $s$ makes all members of the supply chain better-off.

\subsubsection{D-Type Subsidy}

In this subsection, we consider the scenario that the consumer will obtain a discount subsidy when he purchases green products. Assume that the subsidy is related to the environmental quality of green products, that is, $s=\beta e_{4}$; the higher environmental quality of the green product, the higher subsidy, in which $\beta$ and $e_{4}$ represent subsidy coefficient and carbon emission reduction rate of per unit of green product, respectively. Then, the demand function is as follows:

$$
D=a-b\left(p-\beta e_{4}\right)+\tau e_{4} .
$$


Then, the retailer's and manufacturer's profit functions are as follows:

$$
\begin{gathered}
\pi_{r 4}=(p-w) D=(p-w)\left[a-b\left(p-\beta e_{4}\right)+\tau e_{4}\right], \\
\pi_{m 4}=w\left[a-b\left(p-\beta e_{4}\right)+\tau e_{4}\right]-\frac{c_{e} e_{4}{ }^{2}}{2} .
\end{gathered}
$$

The retailer's and manufacturer's utility functions with fairness concern are as follows:

$$
\begin{gathered}
U \pi_{r 4}=\pi_{r 4}-\lambda\left(\pi_{m 4}-\pi_{r 4}\right)=(1+\lambda) \pi_{r 4}-\lambda \pi_{m 4}, \\
U \pi_{m 4}=\pi_{m 4}=w\left[a-b\left(p-\beta e_{4}\right)+\tau e_{4}\right]-\frac{c_{e} e_{4}{ }^{2}}{2},
\end{gathered}
$$

Assumption 2. Consumer environmental awareness satisfies $\tau<2 \sqrt{\frac{b c_{e}(2 \lambda+1)}{\lambda+1}}-b \beta$.

Similar to Assumption 1, with the D-type subsidy, CEA is not larger than a threshold, and the threshold is determined not only by the cost coefficient and the demand sensitivity coefficient to price but also by the level of fairness concern and the subsidy coefficient.

Theorem 7. With D-type subsidy and retailer's fairness concern, the optimal carbon emission reduction rate of green products is as follows:

$$
e_{4}=\frac{a(\lambda+1)(\tau+b \beta)}{4 b c_{e}(2 \lambda+1)-(\lambda+1)(\tau+b \beta)^{2}}
$$

Compared with Theorem 5, we can derive that $e_{4}>e_{3}$; that is, the optimal carbon emission reduction rate with D-type subsidy is much larger than that with F-type subsidy. In other words, the D-type subsidy will stimulate the manufacturer to produce much more environmentally-friendly products.

Theorem 8. With D-type subsidy and retailer's fairness concern, the optimal wholesale price and retail price are as follows:

$$
\begin{aligned}
w_{4} & =\frac{2 a c_{e}(\lambda+1)}{4 b c_{e}(2 \lambda+1)-(\lambda+1)(\tau+b \beta)^{2}}, \\
p_{4} & =\frac{3 a c_{e}(\lambda+1)}{4 b c_{e}(2 \lambda+1)-(\lambda+1)(\tau+b \beta)^{2}} .
\end{aligned}
$$

\section{Proposition 9.}

(i) The optimal carbon emission reduction rate of green products, wholesale price, and retail price increase with CEA;

(ii) The manufacturer's and retailer's profits increase with CEA.

\section{Proposition 10.}

(i) The optimal carbon emission reduction rate, optimal wholesale price, and retail price decrease with $\lambda$;

(ii) The manufacturer's profit decreases with $\lambda$;

(iii) the retailer's profit increases with $\lambda$ when $\lambda<\frac{4 b c_{e}-2(\tau+b \beta)^{2}}{5(\tau+b \beta)^{2}-8 b c_{e}}$ and decreases when $\frac{4 b c_{e}-2(\tau+b \beta)^{2}}{5(\tau+b \beta)^{2}-8 b c_{e}}<\lambda<\frac{4 b c_{e}-(\tau+b \beta)^{2}}{(\tau+b \beta)^{2}-8 b c_{e}}$.

Similar to Propositions 5 and 7, the retailer's profit only increases with fairness concern when the level of the fairness concern is not larger than a threshold; however, differently from Propositions 5 
and 7, the threshold in Proposition 10 is less than that in Propositions 5 and 7. In other words, with the D-type subsidy, the retailer's profit will be more likely to decrease when the retailer is concerned about fairness. In other words, the D-type subsidy decreases the possibility that the retailer increases his profit by paying attention to fairness.

\section{Proposition 11.}

(i) The optimal carbon emission reduction rate, wholesale price, and retail price increase with the subsidy coefficient $\beta$;

(ii) The manufacturer's and retailer's profits increase with government subsidy coefficient $\beta$.

Proposition 11 shows the impact of D-type subsidy on the optimal carbon emission reduction rate, wholesale price, retail price, and manufacturer's and retailer's profits.

In summary, we present the equilibrium carbon emission reduction rates, wholesale prices, and prices of above four scenarios in Table 3; in Table 4, we give the retailer's, manufacturer's profits and retailer's utility with the optimal solutions in Table 3. We use N, F, F-F, and F-D to represent the benchmark model, the model with fairness concern, the model with fairness concern and F-type subsidy, and the model with fairness concern and D-type subsidy, respectively.

Table 3. Optimal carbon emission reduction rates, wholesale prices, and prices.

\begin{tabular}{|c|c|c|c|}
\hline Models & $e^{*}$ & $w^{*}$ & $p^{*}$ \\
\hline $\mathrm{N}$ & $e_{1}=\frac{a \tau}{4 b c_{e}-\tau^{2}}$ & $w_{1}=\frac{2 a c_{e}}{4 b c-\tau^{2}}$ & $p_{1}=\frac{3 a c_{e}}{4 b c_{e}-\tau^{2}}$ \\
\hline F & $e_{2}=\frac{(\lambda+1) a \tau}{4 b c_{e}(2 \lambda+1)-\tau^{2}(\lambda+1)}$ & $w_{2}=\frac{2 a c_{e}(\lambda+1)}{4 b c_{e}(2 \lambda+1)-\tau^{2}(\lambda+1)}$ & $p_{2}=\frac{3 a c_{e}(2 \lambda+1)}{4 b c_{e}(2 \lambda+1)-\tau^{2}(\lambda+1)}$ \\
\hline F-F & $e_{3}=\frac{\tau(\lambda+1)(a+b s)}{4 b c_{e}(2 \lambda+1)-\tau^{2}(\lambda+1)}$ & $\begin{array}{c}w_{3}= \\
\frac{2 c_{e}(\lambda+1)(a+b s)}{4 b c_{e}(2 \lambda+1)-\tau^{2}(\lambda+1)\left(4-3 b^{2}\right)}\end{array}$ & $\begin{array}{c}p_{3}= \\
\frac{3 b^{2} c_{e}(2 \lambda+1)(a+b s)}{4 b c_{e}(2 \lambda+1)-\tau^{2}(\lambda+1)\left(4-3 b^{2}\right)}\end{array}$ \\
\hline F-D & $\begin{array}{c}e_{4}= \\
\frac{a(\lambda+1)(\tau+b \beta)}{4 b c_{e}(2 \lambda+1)-(\lambda+1)(\tau+b \beta)^{2}}\end{array}$ & $\begin{array}{c}w_{4}= \\
\frac{2 c_{e}(\lambda+1)(a+b \beta e i)}{4 b c_{e}(2 \lambda+1)-\tau^{2}(\lambda+1)\left(4-3 b^{2}\right)}\end{array}$ & $\begin{array}{c}p_{4}= \\
\frac{3 b^{2} c_{e}(2 \lambda+1)(a+b \beta e i)}{4 b c_{e}(2 \lambda+1)-\tau^{2}(\lambda+1)\left(4-3 b^{2}\right)}\end{array}$ \\
\hline
\end{tabular}

Table 4. Optimal retailer's profit, manufacturer's profit, and retailer's utility.

\begin{tabular}{|c|c|c|c|}
\hline Models & $\boldsymbol{B}_{r}$ & $\boldsymbol{B}_{m}$ & $U \beta_{r}$ \\
\hline $\mathrm{N}$ & $\pi_{r 1}=\frac{a^{2} b c_{e}^{2}}{\left(4 b c_{e}-\tau^{2}\right)^{2}}$ & $\pi_{m 1}=\frac{a^{2} c_{e}}{2\left(4 b c_{e}-\tau^{2}\right)}$ & $U \pi_{m 1}=\frac{a^{2} b c_{e}^{2}}{\left(4 b c_{e}-\tau^{2}\right)^{2}}$ \\
\hline F & $\begin{array}{c}\pi_{r 2}= \\
\frac{a^{2} b c_{e}^{2}(4 \lambda+1)(2 \lambda+1)}{\left[4 b c_{e}(2 \lambda+1)-\tau^{2}(\lambda+1)\right]^{2}}\end{array}$ & $\begin{array}{c}\pi_{m 2}= \\
\frac{(\lambda+1) a^{2} c_{e}}{2\left[4 b c_{e}(2 \lambda+1)-\tau^{2}(\lambda+1)\right]}\end{array}$ & $\begin{array}{c}U \pi_{r 2}= \\
\frac{a^{2} c_{e}(\lambda+1)\left[\lambda \tau^{2}(\lambda+1)+2 b c_{e}(2 \lambda+1)^{2}\right]}{2\left[4 b c_{e}(2 \lambda+1)-\tau^{2}(\lambda+1)\right]^{2}}\end{array}$ \\
\hline F-F & $\begin{array}{c}\pi_{r 3}= \\
\frac{b c_{e}^{2}(a+b s)^{2}(4 \lambda+1)(2 \lambda+1)}{\left[4 b c_{e}(2 \lambda+1)-\tau^{2}(\lambda+1)\right]^{2}}\end{array}$ & $\begin{array}{c}\pi_{m 3}= \\
\frac{c_{e}(\lambda+1)(a+b s)^{2}}{2\left[4 b c_{e}(2 \lambda+1)-\tau^{2}(\lambda+1)\right]}\end{array}$ & $\begin{array}{c}U \pi_{r 3}= \\
\frac{c_{e}(a+b s)^{2}(\lambda+1)\left[\tau^{2} \lambda(\lambda+1)+2 b c_{e}(2 \lambda+1)^{2}\right]}{2\left[4 b c_{e}(2 \lambda+1)-\tau^{2}(\lambda+1)\right]^{2}}\end{array}$ \\
\hline F-D & $\begin{array}{c}\pi_{r 4}= \\
\frac{a^{2} b c_{e}^{2}(4 \lambda+1)(2 \lambda+1)}{\left[4 b c_{e}(2 \lambda+1)-(\lambda+1)(\tau+b \beta)^{2}\right]^{2}}\end{array}$ & $\begin{array}{c}\pi_{m 4}= \\
\frac{a^{2} c_{e}(\lambda+1)}{2\left[4 b c_{e}(2 \lambda+1)-(\lambda+1)(\tau+b \beta)^{2}\right]}\end{array}$ & $\begin{array}{c}U \pi_{r 4}= \\
\frac{a^{2} c_{e}(\lambda+1)\left[\lambda(\lambda+1) \tau^{2}+2 b c_{e}(2 \lambda+1)^{2}\right]}{2\left[4 b c_{e}(2 \lambda+1)-(\lambda+1)(\tau+b \beta)^{2}\right]^{2}}\end{array}$ \\
\hline
\end{tabular}

\section{Numerical Examples}

To illustrate our conclusions more intuitively, we present the numerical analyses in this section. We give some numerical examples to analyze the changing trends of the optimal carbon emission reduction rate, wholesale price, retail price, manufacturer's profit, retailer's profit, and retailer's utility with government subsidies and retailer's fairness concern in the four models, respectively. 
For the purpose of our numerical demonstration, the parameters are specified as follows: $a=10, b=1, c_{e}=0.5, \tau=0.5, \lambda=0.5, s=2, \beta=0.5$. We consider these parameters are consistent with our assumptions and industrial practices.

\subsection{The Impact of Retailer's Fairness Concern $\lambda$ on Supply Chain}

In this subsection, we mainly explore the change trends of the optimal carbon emission reduction rate, wholesale price, retail price, manufacturer's profit, retailer's price, and retailer's utility with the retailer's fairness concern coefficient $\lambda$.

Figures 1 and 2 show the change trends of the optimal strategies with retailer's fairness concern $\lambda$. Figure 1 shows that the optimal carbon emission reduction rate, wholesale price, and retailer price decrease with $\lambda$. Figure 2 indicates that the optimal manufacturer's profit decreases with $\lambda$, while the optimal utility and profit of the retailer increase with $\lambda$. In above examples, the thresholds of the fairness concern are less than zero; hence, the retailer's profits increase $\lambda$.These results are in accordance with Propositions 4, 5, 7, and 10.

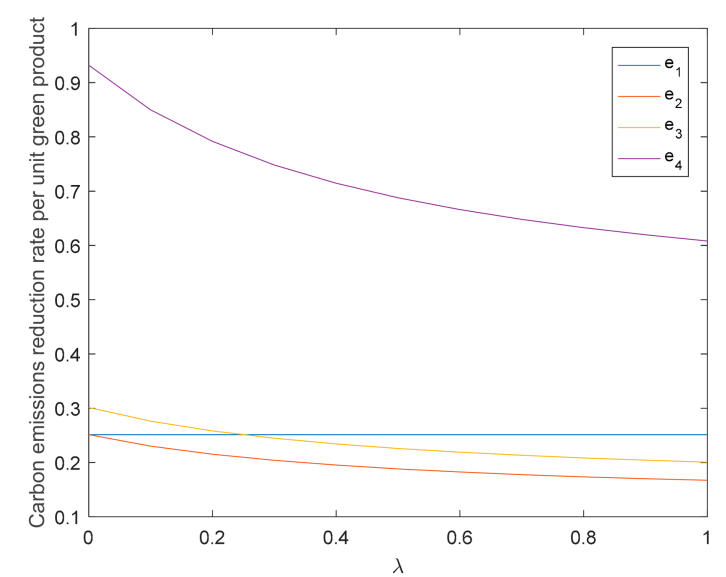

(a)

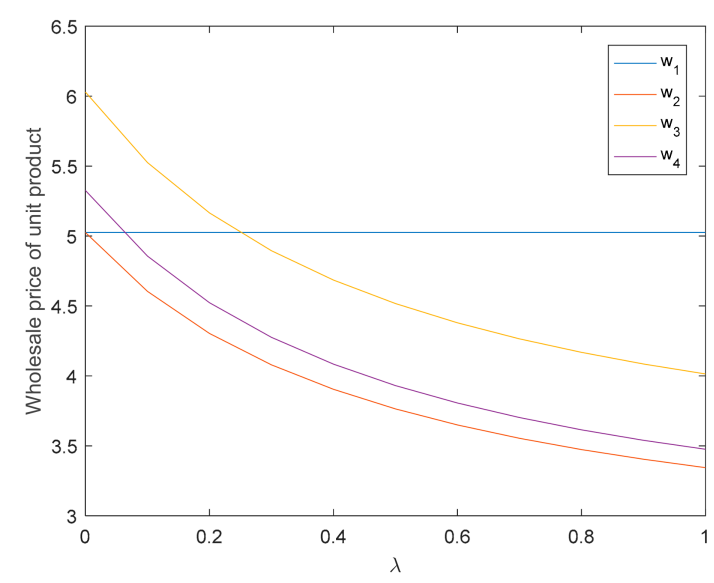

(b)

Figure 1. Cont. 


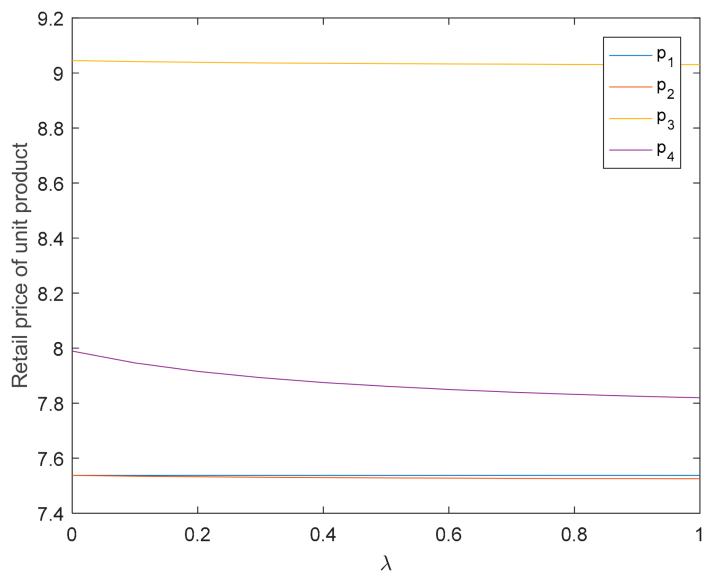

(c)

Figure 1. (a) The optimal carbon emission reduction rate, (b) wholesale price, and (c) retail price as a function of $\lambda$.

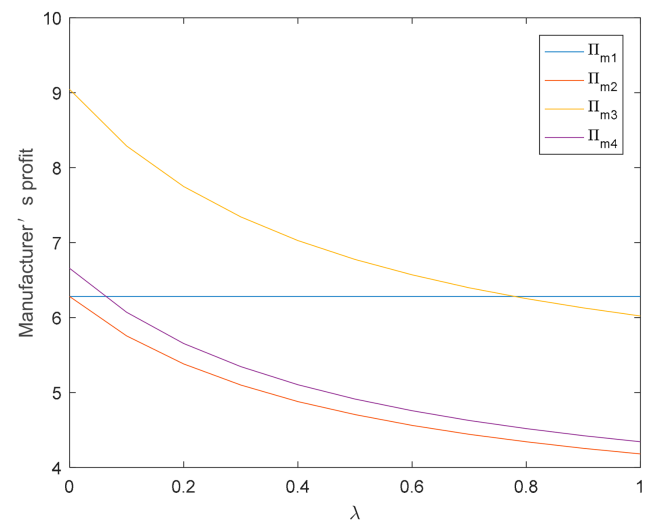

(a)

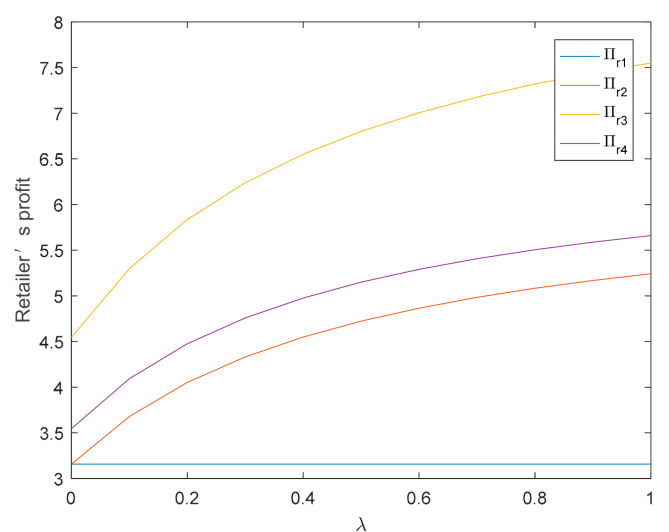

(b)

Figure 2. Cont. 


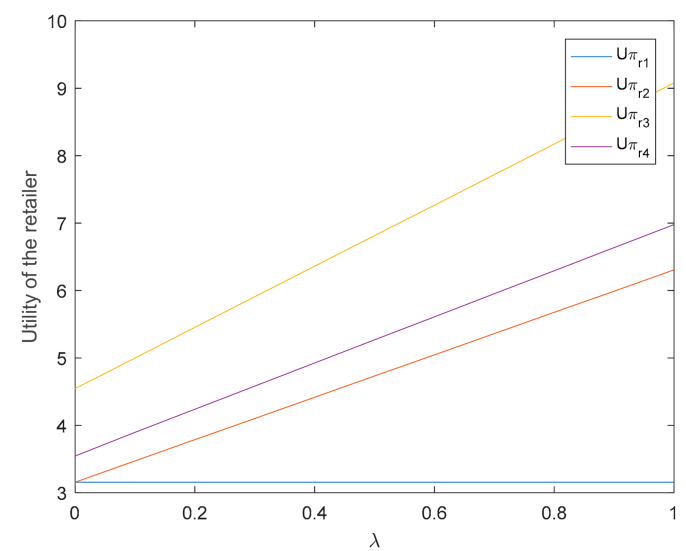

(c)

Figure 2. (a) The optimal manufacturer's profit, (b) retailer's profit, (c) and the retailer's utility as a function of $\lambda$.

\subsection{The Impact of Fixed Subsidy s on Supply Chain}

In this subsection, we mainly explore the change trends of the optimal carbon emission reduction rate, wholesale price, retail price, manufacturer's profit, retailer's price, and retailer's utility with the fixed subsidy $s$.

Figures 3 and 4 show how the fixed-type subsidy $s$ impacts the supply chain members' strategies. Because only Section 4.2.1 is related to F-type subsidy, the other three scenarios keep constants with s.

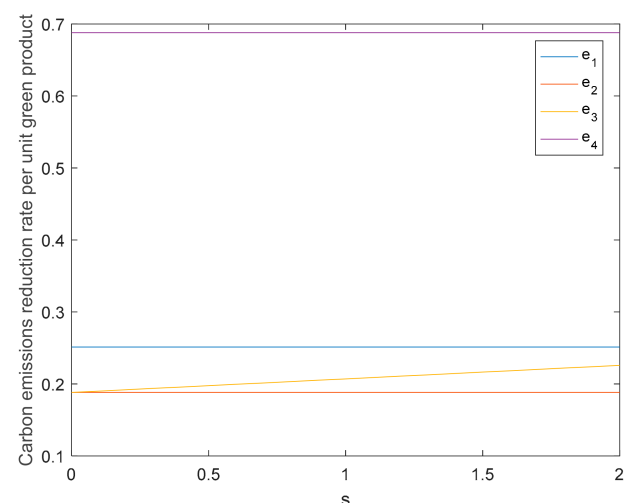

(a)

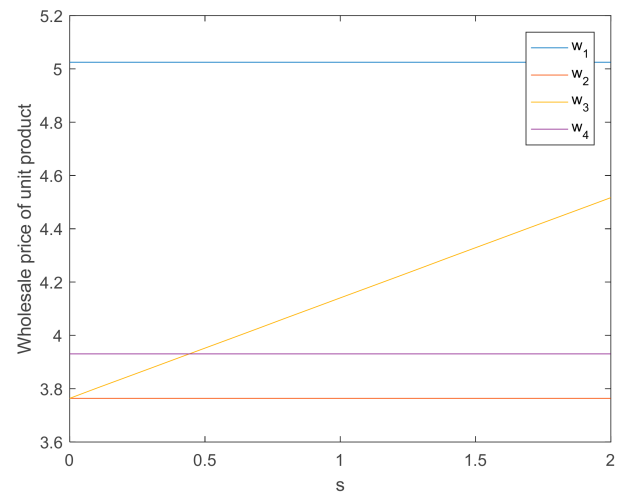

(b)

Figure 3. Cont. 


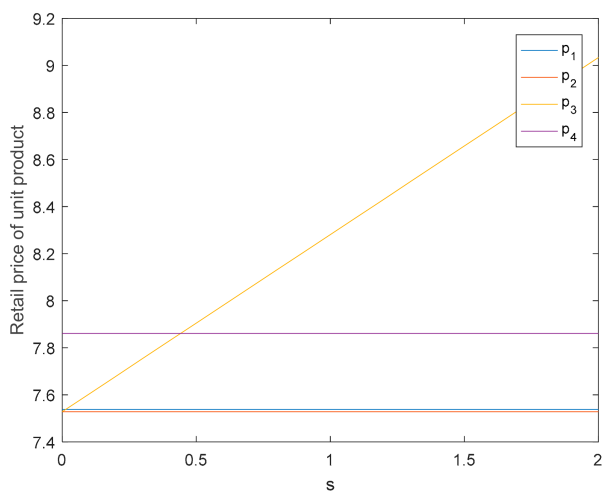

(c)

Figure 3. (a) The optimal carbon emission reduction rate, (b) wholesale price, and (c) retail price as a function of $s$.

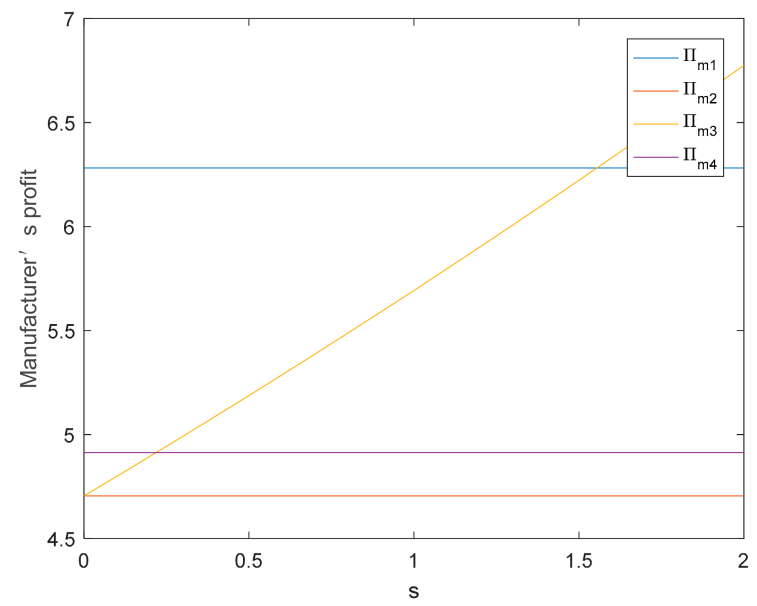

(a)

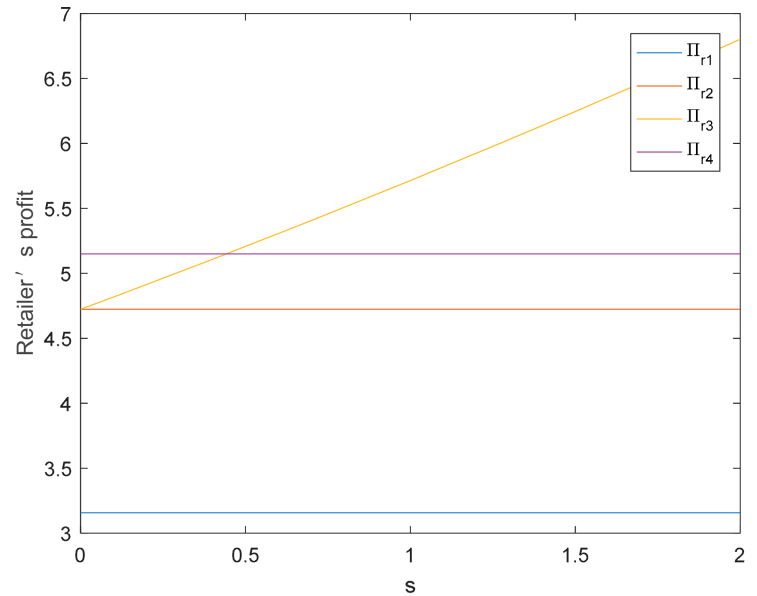

(b)

Figure 4. Cont. 


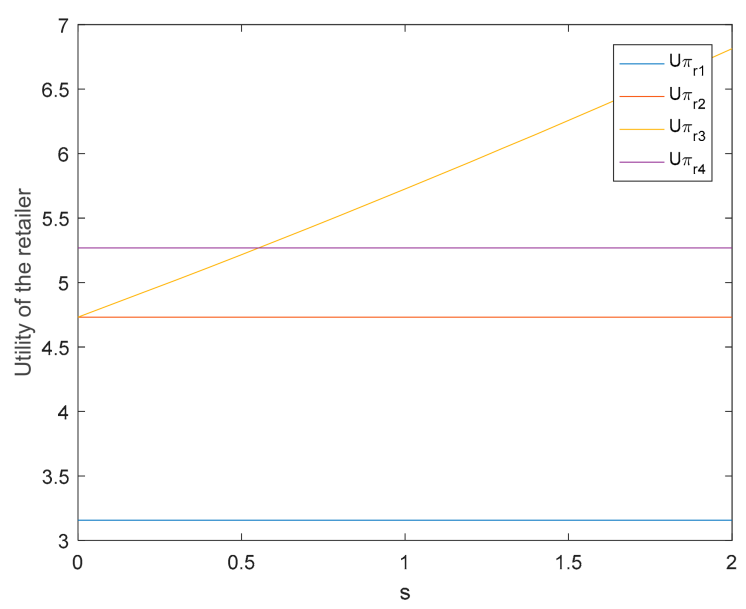

(c)

Figure 4. (a) The optimal manufacturer's profit, (b) retailer's profit, and (c) retailer's utility as a function of $s$.

Figures 3 and 4 show that the optimal carbon emission reduction rate, wholesale price, retailer price, and profit increase with $s$ are in accordance with Proposition 8. Moreover, the impact of the F-type subsidy on the retailer's price and profit is much more significant than that on the carbon emission reduction rate. In other words, the F-type subsidy could bring more money to the manufacturer but is less effective at stimulating the manufacturer to produce greener products.

\subsection{The Impact of D-Type Subsidy Coefficient $\beta$ on Supply Chain}

In this subsection, we mainly explore the change trends of the optimal carbon emission reduction rate, wholesale price, retail price, manufacturer's profit, retailer's price, and retailer's utility with the discount subsidy coefficient $\beta$.

Figures 5 and 6 show how the discount subsidy coefficient $\beta$ impacts the supply chain members' strategies. Because only Section 4.2.2 is related to D-type subsidy, the other three scenarios keep constant with $\beta$.

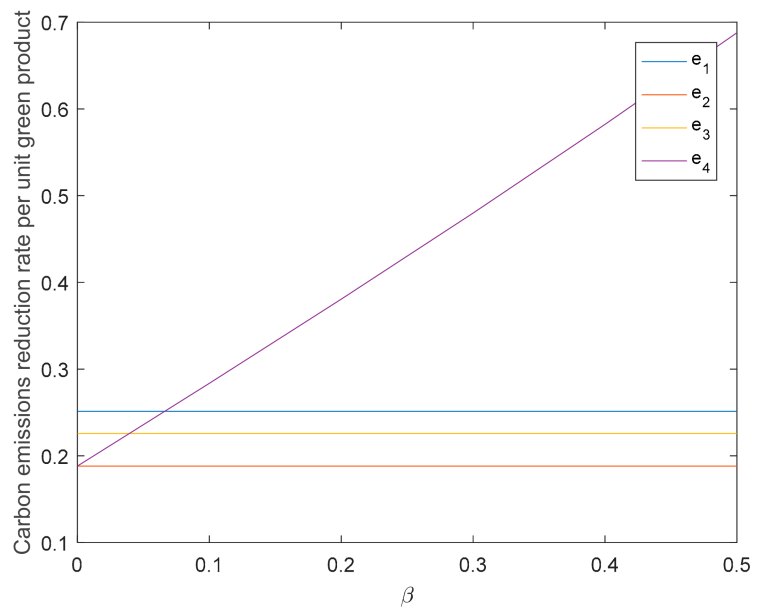

(a)

Figure 5. Cont. 


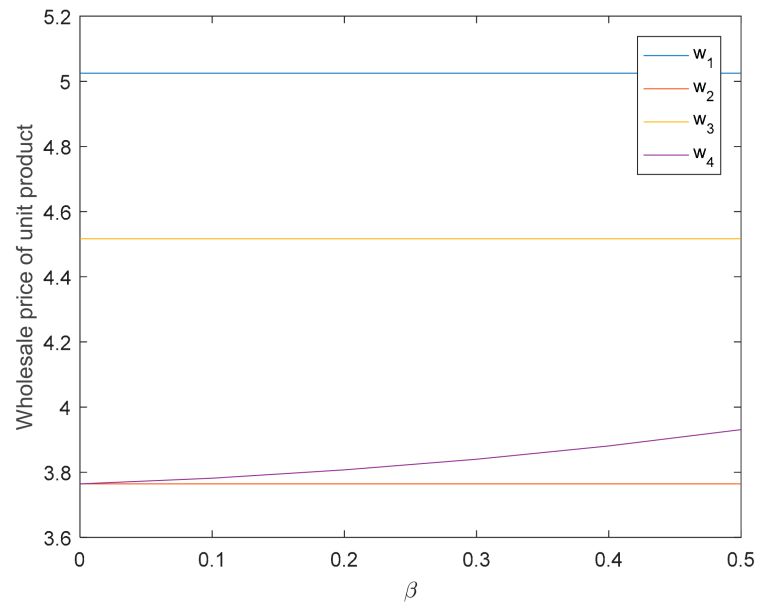

(b)

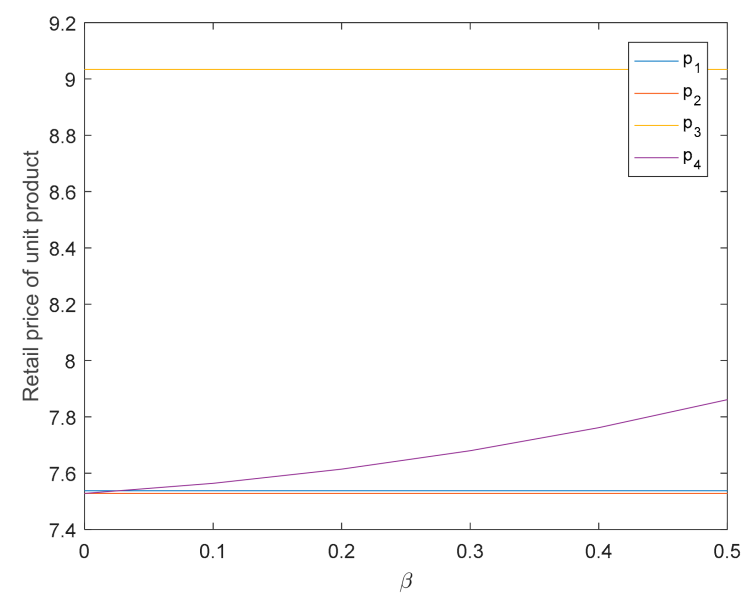

(c)

Figure 5. (a) The optimal carbon emission reduction rate, (b) wholesale price, and (c) retail price as a function of $\beta$.

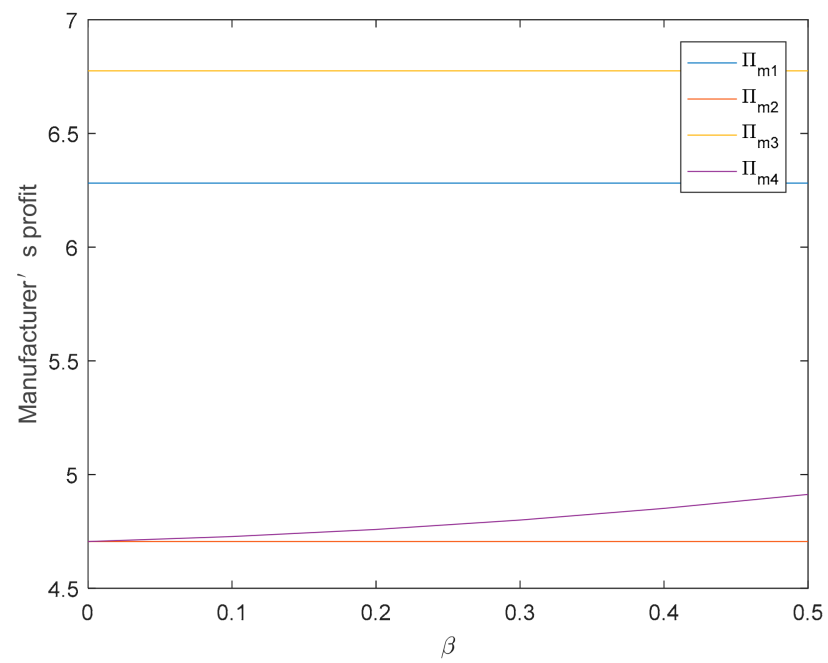

(a)

Figure 6. Cont. 


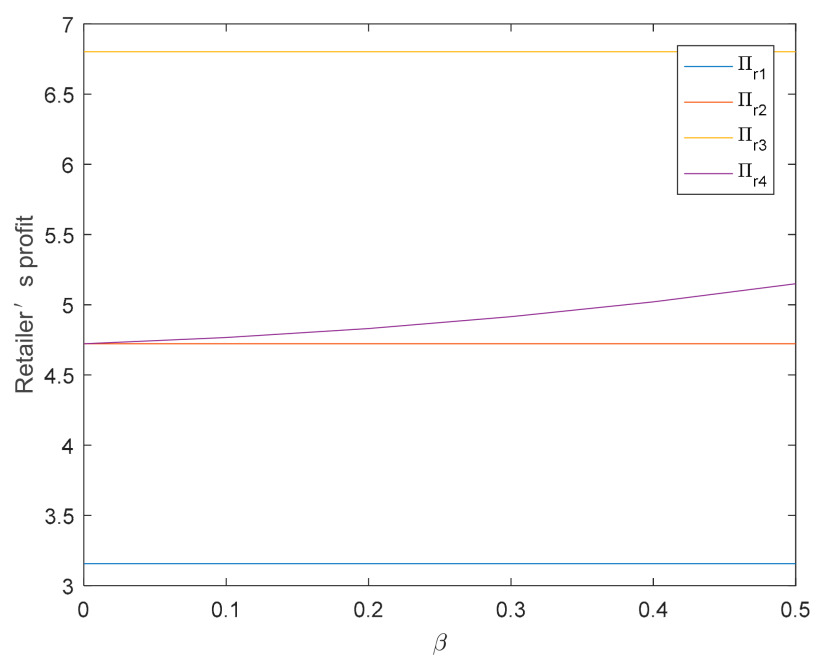

(b)

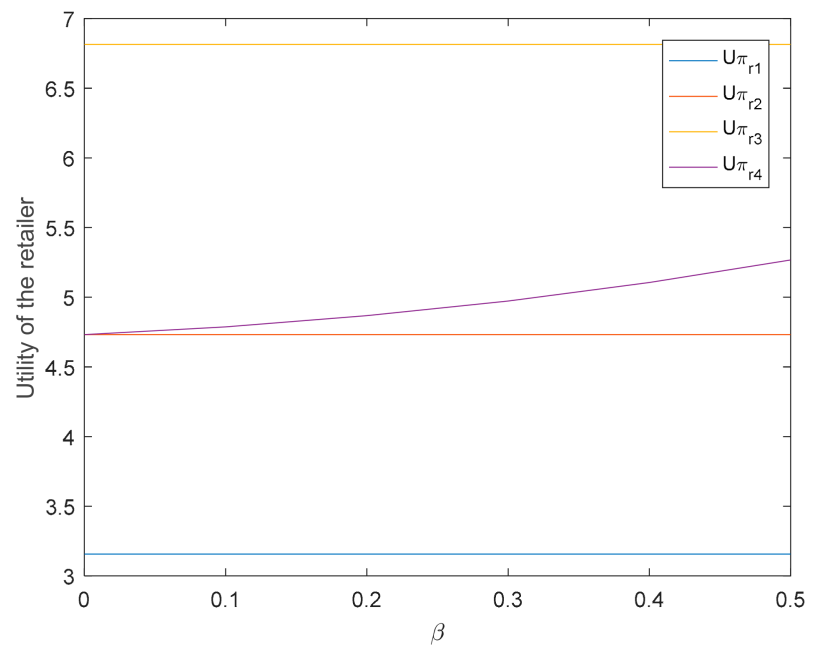

(c)

Figure 6. (a) The optimal manufacturer's profit, (b) retailer's profit, and (c) retailer's utility as a function of $\beta$.

Figure 5 shows that the optimal carbon emission reduction rate, wholesale price, price, retailer's and manufacturer's profits, and retailer's utility increase with $\beta$, which is in accordance with Proposition 11. Compared with the F-type subsidy, the D-type subsidy has more significant effect on improving the carbon emission reduction rate.

\section{Discussion and Conclusions}

Consumers and manufacturers are increasingly making an effort to be eco-friendly [2] and the government also implements some subsidy policies. However, the retailer may not benefit from selling green products or feeling hard done by. In this paper, we assume that there is one manufacturer and one retailer in a supply chain, and green products with low carbon emission levels are provided in the supply chain. While the retailer is concerned about fairness and government implements subsidies to the consumer who purchases green products, we mainly study the optimal carbon emission reduction rate of green products, the wholesale price, retail price, and their change trends with CEA, fairness concern, and subsidies. Therefore, our study shows how the retailer's fairness concern and government subsidies impact the optimal carbon emission reduction rate, the price, and supply chain members' profits. 


\subsection{Managerial Implications}

Our study has four main managerial implications. Firstly, high consumer environmental awareness will benefit both the manufacturer and the retailer whether the retailer is concerned about fairness or not or whether there is F-type or D-type subsidy. Therefore, government and the firm could combine to do more effort to improve the public's environmental awareness; secondly, when the retailer cares about fairness, the optimal carbon emission reduction rate of green product, wholesale price, and price will reduce, but when there is a government subsidy, the optimal strategies will increase. In other words, fairness concern and subsidies have counter effect on optimal strategies; the subsidy could alleviate the negative influence caused by retailer's fairness concern; thirdly, retailer's fairness concern reduces manufacturer's profit and impels the manufacturer to produce product with high carbon emission. Therefore, the government could subsidize the retailer when there is unfairness in the supply chain so that the manufacturer could produce products with low carbon emission levels; finally, compared with F-type subsidy, the D-type subsidy will be more effective at stimulating the manufacturer to produce much more environment-friendly product. Therefore, using the subsidy related to environmental quality will be more helpful to improve environment quality, especially when the government has the budget constraint.

\subsection{Limitations and Future Research}

Our model has certain limitations. Firstly, in order to simplify the problem, we only analyze two echelon supply chains with one manufacturer and one retailer without taking the multi-echelon supply chain, and we also do not consider the fairness concern of the other members in the supply chain. Moreover, the conclusions obtained in this paper are only derived from theoretical models, and how to combine the relevant cases and make empirical analysis to make up for these deficiencies will be the problems that need further study in order to be solved in the future. Therefore, there are three research directions: first, the impact of fairness concern on multi-echelon supply chain could be studied; second, other members' fairness concern could be explored, such as the manufacturer, and the fairness between the competitive retailers and the competitive manufacturers (distributional fairness and horizon fairness) could be investigated simultaneously; third, the manufacturer may not choose the carbon emission level randomly because of the technology constraint and budget constraint; hence, combining with the practical background of the manufacturer and giving more specific suggestions is also a research direction.

Acknowledgments: This work was supported by the National Nature Science Foundation of China (Grant Numbers 71602103 and 61472231), Shandong Normal University (Grant Number 15SQR017).

Author Contributions: Linghong Zhang conceived the paper. Bowen Xue and Xiyu Liu designed the algorithms to solve the models. Linghong Zhang and Bowen Xue wrote the paper.

Conflicts of Interest: The authors declare no conflict of interest.

\section{Appendix}

\section{Proofs of Theorem 1 and Theorem 2.}

As we know, the demand function for the green products is

$$
D=a-b p+\tau e(a>0, b>0) .
$$

The retailer's profit function is:

$$
\pi r=(p-w) D=(p-w)(a-b p+\tau e) .
$$


The profit function of the manufacturer is

$$
\pi_{m}=w D-\frac{c_{e} e^{2}}{2}=w(a-b p+\tau e)-\frac{c_{e} e^{2}}{2} .
$$

The utility function of supply chain is

$$
U \pi_{s}=U \pi_{r}+\pi_{m}
$$

Since $\frac{\partial^{2} \pi_{r}}{\partial p^{2}}=-2 b<0$, we have $\frac{\partial \pi_{r}}{\partial p}=-2 b p+(a+\tau e+b w)=0$ and get the optimal price for retailers:

$$
p_{1}=\frac{a+\tau e+b w}{2 b} .
$$

Then, the manufacturer's profit is:

$$
\pi_{m 1}=\frac{-b w^{2}+(a+\tau e) w-c_{e} e^{2}}{2} .
$$

Since $\frac{\partial^{2} \pi_{m}}{\partial w^{2}}=-\frac{1}{2} b<0$, we have $\frac{\partial \pi_{m 1}}{\partial w}=-b w+\frac{1}{2}(a+\tau e+b w)=0$ and get the optimal wholesale price for manufacturers:

$$
w_{1}=\frac{a+\tau e}{2 b}
$$

Then, the optimal price for retailer is

$$
p_{1}=\frac{3(a+\tau e)}{4 b} .
$$

Then the retailer's profit and utility are

$$
\begin{gathered}
\pi_{r 1}=\frac{(a+\tau e)^{2}}{16 b} \\
U \pi_{r 1}=\frac{(a+\tau e)^{2}}{16 b} .
\end{gathered}
$$

The manufacturer's profit is

$$
\pi_{m 1}=\frac{(a+\tau e)^{2}}{8 b}-\frac{c_{e} e^{2}}{2} .
$$

Since $\frac{\partial^{2} \pi_{m 1}}{\partial e^{2}}=\frac{\tau^{2}-4 b c_{e}}{4 b}$, only when $\tau^{2}-4 b c_{e}<0 \Rightarrow \tau<2 \sqrt{b c_{e}}$ can we get the optimal profit of the manufacturer. We have $\frac{\pi_{m 1} 1}{\partial e}=\frac{a \tau+\left(\tau^{2}-4 b c_{e}\right) e}{4 b}=0$ and get the optimal environmental quality

$$
e_{1}=\frac{a \tau}{4 b c_{e}-\tau^{2}}, \tau<2 \sqrt{b c_{e}}
$$

We finally get that

$$
\begin{aligned}
& w_{1}=\frac{2 a c_{e}}{4 b c-\tau^{2}} \\
& p_{1}=\frac{3 a c_{e}}{4 b c_{e}-\tau^{2}}
\end{aligned}
$$

Proof of Proposition 1.

$$
\frac{\partial e_{1}}{\partial \tau}=\frac{4 a b c_{e}+a \tau^{2}}{\left(4 b c_{e}-\tau^{2}\right)^{2}}>0 .
$$

Proof of Proposition 2. 
Under the premise of $\tau<2 \sqrt{b c_{e}}$, the first derivative of the optimal retail price, optimal wholesale price, manufacturer's profit, retailer's profit, and supply chain's utility on $\tau$ is as follows:

$$
\begin{gathered}
\frac{\partial w_{1}}{\partial \tau}=\frac{4 a c_{e} \tau}{\left(4 b c_{e}-\tau^{2}\right)^{2}}>0 \\
\frac{\partial p_{1}}{\partial \tau}=\frac{6 a c_{e} \tau}{\left(4 b c_{e}-\tau^{2}\right)^{2}}>0 \\
\frac{\partial \pi_{m 1}}{\partial \tau}=\frac{a^{2} c_{e} \tau}{\left(4 b c_{e}-\tau^{2}\right)^{2}}>0 ; \\
\frac{\partial \pi_{r 1}}{\partial \tau}=\frac{4 a^{2} b c_{e}^{2} \tau}{\left(4 b c_{e}-\tau^{2}\right)^{2}}>0 \\
\frac{\partial U \pi_{s 1}}{\partial \tau}=\frac{a^{2} c_{e} \tau\left(8 b c_{e}-\tau^{2}\right)}{\left(4 b c_{e}-\tau^{2}\right)^{3}}>0 .
\end{gathered}
$$

Proofs of Theorem 3 and Theorem 4.

$$
U \pi_{r 2}=\pi_{r 2}-\lambda\left(\pi_{m 2}-\pi_{r 2}\right)=(1+\lambda) \pi_{r 2}-\lambda \pi_{m 2} ;
$$

Since $\frac{\partial^{2} U \pi_{r 2}}{\partial p^{2}}=-2 b(\lambda+1)<0$, we have $\frac{\partial U \pi_{r 2}}{\partial p^{2}}=-b(p-w)(1+\lambda)+(1+\lambda)(a+\tau e+b w)+$ $b \lambda w=0$ and get the optimal price for retailers:

$$
p_{2}=\frac{(1+\lambda)(a+\tau e+b w)+b \lambda w}{2 b(1+\lambda)} .
$$

The manufacturer's profit is:

$$
\pi_{m 2}=\frac{w[(\lambda+1)(a+\tau e)-b w(2 \lambda+1)]}{2}-\frac{c_{e} e^{2}}{2} .
$$

Since $\frac{\partial^{2} \pi_{m 2}}{\partial w^{2}}=\frac{-2 b \lambda-b}{\lambda+1}<0$, we have $\frac{\partial \pi_{m 2}}{\partial w}=\frac{-2 b w(1+2 \lambda)+(1+\lambda)(a+\tau e)}{2(\lambda+1)}=0$ and get the optimal wholesale price

$$
w_{2}=\frac{(\lambda+1)(a+\tau e)}{2 b(2 \lambda+1)} .
$$

The optimal price for retailer is

$$
p_{2}=\frac{3(a+\tau e)}{4 b}
$$

The retailer's profit is

$$
\pi_{r 2}=\frac{(4 \lambda+1)(a+\tau e)^{2}}{16 b(2 \lambda+1)}
$$

The manufacturer's profit is

$$
\pi_{m 2}=\frac{(\lambda+1)(a+\tau e)^{2}}{8 b(2 \lambda+1)}-\frac{c_{e} e^{2}}{2} .
$$


Since $\frac{\partial^{2} \pi_{m 2}}{\partial e^{2}}=\frac{\tau^{2}(1+\lambda)-4 b(2 \lambda+1)}{4 b(2 \lambda+1)}$, only when $\tau^{2}(1+\lambda)-4 b(2 \lambda+1)<0 \Rightarrow \tau<\sqrt{\frac{4 b(2 \lambda+1)}{1+\lambda}}$ can we get the optimal profit of the manufacturer. We have $\frac{\partial \pi_{m 2}}{\partial e}=\frac{a(\lambda+1) \tau+\left[\tau^{2}(\lambda+1)-4 b(2 \lambda+1)\right] e}{4 b(2 \lambda+1)}=0$ and get the optimal environmental quality of green products for manufacturers:

$$
e_{2}=\frac{a(\lambda+1) \tau}{4 b c_{e}(2 \lambda+1)-\tau^{2}(\lambda+1)}>0 \tau<\sqrt{\frac{4 b c_{e}(2 \lambda+1)}{1+\lambda}} .
$$

Then, we get

$$
\begin{aligned}
& w_{2}=\frac{2 a c_{e}(\lambda+1)}{4 b c_{e}(2 \lambda+1)-\tau^{2}(\lambda+1)} ; \\
& p_{2}=\frac{3 a c_{e}(2 \lambda+1)}{4 b c_{e}(2 \lambda+1)-\tau^{2}(\lambda+1)} .
\end{aligned}
$$

\section{Proof of Proposition 3.}

The first derivative of the optimal retail price, optimal wholesale price, manufacturer's profit, and retailer's profit on $\tau$ is as follows.

$$
\begin{gathered}
\frac{\partial e 2}{\partial \tau}=\frac{a(\lambda+1)\left[4 b c_{e}(2 \lambda+1)+\tau^{2}(\lambda+1)\right]}{\left[4 b c_{e}(2 \lambda+1)-\tau^{2}(\lambda+1)\right]^{2}}>0 ; \\
\frac{\partial w 2}{\partial \tau}=\frac{4 a c_{e} \tau(\lambda+1)^{2}}{\left[4 b c_{e}(2 \lambda+1)-\tau^{2}(\lambda+1)\right]^{2}}>0 ; \\
\frac{\partial p 2}{\partial \tau}=\frac{6 a c_{e} \tau(2 \lambda+1)(\lambda+1)}{\left[4 b c_{e}(2 \lambda+1)-\tau^{2}(\lambda+1)\right]^{2}}>0 ; \\
\frac{\partial \pi m 2}{\partial \tau}=\frac{a^{2} c_{e} \tau(\lambda+1)^{2}}{8 b(2 \lambda+1)^{2}}>0 ; \\
\frac{\partial \pi r 2}{\partial \tau}=\frac{3 a^{2} b c e^{2} \tau\left(8 \lambda^{3}+14 \lambda^{2}+7 \lambda+1\right)}{\left[4 b c e(2 \lambda+1)-\tau^{2}(\lambda+1)\right]^{3}}>0 .
\end{gathered}
$$

\section{Proof of Proposition 4.}

The first derivative of the optimal retail price and optimal wholesale price on $\lambda$ is as follows.

$$
\begin{aligned}
& \frac{\partial e_{2}}{\partial \lambda}=\frac{-4 a b c_{e} \tau}{\left[4 b c_{e}(2 \lambda+1)-\tau^{2}(\lambda+1)\right]^{2}}<0 \\
& \frac{\partial w 2}{\partial \lambda}=\frac{-8 a b c_{e}^{2}}{\left[4 b c_{e}(2 \lambda+1)-\tau^{2}(\lambda+1)\right]^{2}}<0 \\
& \frac{\partial p 2}{\partial \lambda}=\frac{-3 a c_{e} \tau^{2}}{\left[4 b c_{e}(2 \lambda+1)-\tau^{2}(\lambda+1)\right]^{2}}<0
\end{aligned}
$$

Proof of Proposition 5.

(i) $\frac{\partial \pi_{r 2}}{\partial \lambda}=\frac{2 a^{2} b c e\left[4 b c_{e}(2 \lambda+1)-\tau^{2}(5 \lambda+2)\right]}{\left[4 b c e(2 \lambda+1)-\tau^{2}(\lambda+1)\right]^{2}}<0 \Rightarrow \frac{4 b c_{e}-2 \tau^{2}}{5 \tau^{2}-8 b c_{e}}<\lambda<\frac{4 b c_{e}-\tau^{2}}{\tau^{2}-8 b c_{e}}$ and $\frac{\partial \pi_{r 2}}{\partial \lambda}=\frac{2 a^{2} b c_{e}\left[4 b c_{e}(2 \lambda+1)-\tau^{2}(5 \lambda+2)\right]}{\left[4 b c_{e}(2 \lambda+1)-\tau^{2}(\lambda+1)\right]^{2}}>0 \Rightarrow \lambda<\frac{4 b c_{e}-2 \tau^{2}}{5 \tau^{2}-8 b c_{e}}$

(ii) $\frac{\partial \pi_{m 2}}{\partial \lambda}=-\frac{(a+e \tau)^{2}}{8 b(2 \lambda+1)^{2}}<0$. 


\section{Proofs of Theorem 5 and Theorem 6.}

Now, the profit functions are:

$$
\pi_{r 3}=(p-w) D=(p-w)[a-b(p-s)+\tau e] ; \pi_{m 3}=w D-\frac{c_{e} e^{2}}{2}=w[a-b(p-s)+\tau e]-\frac{c_{e} e^{2}}{2} .
$$

Since $\frac{\partial^{2} U \pi_{r 3}}{\partial p_{3}{ }^{2}}=-2 b(\lambda+1)<0$, we have $\frac{\partial U \pi_{r 3}}{\partial p_{3}}=0$ and get the optimal price for retailers:

$$
p_{3}=\frac{(1+\lambda)(a+\tau e+b w)+b w(2 \lambda+1)}{2 b(1+\lambda)} .
$$

Then, the manufacturer's profit is

$$
\pi_{m 3}=w\left[a+\tau e+\frac{(\lambda+1)(b s-a-\tau e)+b w(2 \lambda+1)}{2(\lambda+1)}\right]-\frac{c_{e} e^{2}}{2} .
$$

Since $\frac{\partial^{2} \pi_{m 3}}{\partial w_{3}{ }^{2}}=\frac{-2 b \lambda-b}{\lambda+1}<0$, we have $\frac{\partial \pi_{m 3}}{\partial w_{3}}=0$ and get the optimal wholesale price for manufacturers

$$
w_{3}=\frac{(\lambda+1)(a+\tau e+b s)}{2 b(2 \lambda+1)} .
$$

Then, we get the manufacturer's profit

$$
\pi_{m 3}=\frac{\left(4-3 b^{2}\right)(\lambda+1)(a+b s+\tau e)^{2}}{8 b(2 \lambda+1)}-\frac{c_{e} e^{2}}{2} .
$$

Only when $\tau<2 \sqrt{\frac{b c_{e}(2 \lambda+1)}{1+\lambda}}$ can we get the optimal manufacturer's profit. We have $\frac{\partial \pi_{m 3}}{\partial e}=0$ and get the optimal environmental quality of green products for manufacturers $e 3=\frac{\tau(\lambda+1)(a+b s)}{4 b c_{e}(2 \lambda+1)-\tau^{2}(\lambda+1)}>0$.

Then, we get

$$
\begin{aligned}
& w_{3}=\frac{2 c_{e}(a+b s)(\lambda+1)}{4 b c_{e}(2 \lambda+1)-\tau^{2}(\lambda+1)} ; \\
& p_{3}=\frac{3 c_{e}(2 \lambda+1)(a+b s)}{4 b c_{e}(2 \lambda+1)-\tau^{2}(\lambda+1)} .
\end{aligned}
$$

\section{Proof of Proposition 6.}

With F-type government subsidies and retailer's fairness concern, we get

$$
\begin{gathered}
\frac{\partial e_{3}}{\partial \tau}=\frac{(\lambda+1)(a+b s)\left[4 b c_{e}(2 \lambda+1)+\tau^{2}(\lambda+1)\right]}{\left[4 b c_{e}(2 \lambda+1)-\tau^{2}(\lambda+1)\right]^{2}}>0 ; \\
\frac{\partial w 3}{\partial \tau}=\frac{4 c_{e} \tau(\lambda+1)^{2}(a+b s)}{\left[4 b c_{e}(2 \lambda+1)-\tau^{2}(\lambda+1)\right]^{2}}>0 ; \\
\frac{\partial p_{3}}{\partial \tau}=\frac{6 c_{e} \tau(a+b s)\left(2 \lambda^{2}+3 \lambda+1\right)}{\left[4 b c_{e}(2 \lambda+1)-\tau^{2}(\lambda+1)\right]^{2}}>0 ; \\
\frac{\partial \pi_{m 3}}{\partial \tau}=\frac{c_{e} \tau(a+b s)^{2}(\lambda+1)^{2}}{\left[4 b c_{e}(2 \lambda+1)-\tau^{2}(\lambda+1)\right]^{2}}>0 ; \\
\frac{\partial \pi_{r 3}}{\partial \tau}=\frac{4 b c_{e}{ }^{2} \tau(a+b s)^{2}\left(8 \lambda^{3}+14 \lambda^{2}+7 \lambda+1\right)}{\left[4 b c_{e}(2 \lambda+1)-\tau^{2}(\lambda+1)\right]^{3}}>0 .
\end{gathered}
$$




\section{Proof of Proposition 7.}

With F-type government subsidies and retailer's fairness concern, we get

$$
\begin{aligned}
& \frac{\partial e_{3}}{\partial \lambda}=\frac{-4 b c_{e} \tau(a+b s)}{\left[4 b c_{e}(2 \lambda+1)-\tau^{2}(\lambda+1)\right]^{2}}<0 ; \\
& \frac{\partial w_{3}}{\partial \lambda}=\frac{-8 b c_{e}^{2}(a+b s)}{\left[4 b c_{e}(2 \lambda+1)-\tau^{2}(\lambda+1)\right]^{2}}<0 ; \\
& \frac{\partial p_{3}}{\partial \lambda}=\frac{-3 c_{e} \tau^{2}(a+b s)}{\left[4 b c_{e}(2 \lambda+1)-\tau^{2}(\lambda+1)\right]^{2}}<0 ; \\
& \frac{\partial \pi_{m 3}}{\partial \lambda}=\frac{-2 b c_{e}^{2}(a+b s)^{2}}{\left[4 b c_{e}(2 \lambda+1)-\tau^{2}(\lambda+1)\right]^{2}}<0 ; \\
& \frac{\partial \pi_{r 3}}{\partial \lambda}=\frac{2 b c_{e}^{2}(a+b s)^{2}\left[4 b c_{e}(2 \lambda+1)-\tau^{2}(5 \lambda+2)\right]}{\left[4 b c_{e}(2 \lambda+1)-\tau^{2}(\lambda+1)\right]^{3}}>0 \\
& \Rightarrow \lambda<\frac{4 b c_{e}-2 \tau^{2}}{5 \tau^{2}-8 b c_{e}}{ }^{2}\left[4 b c_{e}(2 \lambda+1)-\tau^{2}(5 \lambda+2)\right] \\
& \frac{\partial \pi_{r 3}}{\partial \lambda}=\frac{2 b c_{e}^{2}(a+b s)^{2}\left[4 c_{e}\right.}{\left[4 b c_{e}(2 \lambda+1)-\tau^{2}(\lambda+1)\right]^{3}}<0 \\
& \Rightarrow \frac{4 b c_{e}-2 \tau^{2}}{5 \tau^{2}-8 b c_{e}}<\lambda<\frac{4 b c_{e}-\tau^{2}}{\tau^{2}-8 b c_{e}}
\end{aligned}
$$

\section{Proof of Proposition 8.}

With F-type government subsidies and retailer's fairness concern, we get

$$
\begin{gathered}
\frac{\partial e_{3}}{\partial s}=\frac{b \tau(\lambda+1)}{4 b c_{e}(2 \lambda+1)-\tau^{2}(\lambda+1)}>0 ; \\
\frac{\partial w_{3}}{\partial s}=\frac{2 b c_{e}(\lambda+1)}{4 b c_{e}(2 \lambda+1)-\tau^{2}(\lambda+1)}>0 ; \\
\frac{\partial p_{3}}{\partial s}=\frac{3 b c_{e}(2 \lambda+1)}{4 b c_{e}(2 \lambda+1)-\tau^{2}(\lambda+1)}>0 ; \\
\frac{\partial \pi_{m 3}}{\partial s}=\frac{b c_{e}(a+b s)(\lambda+1)}{4 b c_{e}(2 \lambda+1)-\tau^{2}(\lambda+1)}>0 ; \\
\frac{\partial \pi_{r 3}}{\partial s}=\frac{2 b^{2} c_{e}^{2}(2 \lambda+1)(4 \lambda+1)(a+b s)}{\left[4 b c_{e}(2 \lambda+1)-\tau^{2}(\lambda+1)\right]^{2}}>0 .
\end{gathered}
$$

Proofs of Theorem 7 and Theorem 8.

$$
\begin{gathered}
D=a-b\left(p-\beta e_{4}\right)+\tau e_{4} ; \\
\pi_{r 4}=(p-w) D=(p-w)\left[a-b\left(p-\beta e_{4}\right)+\tau e_{4}\right] ; \\
\pi_{m 4}=w\left[a-b\left(p-\beta e_{4}\right)+\tau e_{4}\right]-\frac{c_{e} e_{4}{ }^{2}}{2} .
\end{gathered}
$$

Since $\frac{\partial^{2} U \pi_{r 4}}{\partial p 4^{2}}=-2 b(\lambda+1)<0$, we have $\frac{\partial U \pi_{r 4}}{\partial p 4}=0$ and get the optimal price for retailers: $p_{4}=\frac{(1+\lambda)(a+\tau e+b w+b \beta e)+b \lambda w}{2 b(1+\lambda)}$.

Then the manufacturer's profit is

$$
\pi_{m 4}=w\left[a+\tau e++b \beta e-\frac{(\lambda+1)(a+\tau e+b w+b \beta e)+b w \lambda}{2(\lambda+1)}\right]-\frac{c_{e} e^{2}}{2} .
$$


Since $\frac{\partial^{2} \pi_{m 4}}{\partial w 4^{2}}=<0$, we have $\frac{\partial \pi_{m 4}}{\partial w_{4}}=0$ and get the optimal wholesale price

$$
w_{4}=\frac{(\lambda+1)(a+\tau e+b \beta e)}{2 b(2 \lambda+1)} .
$$

Only when $\tau<2 \sqrt{\frac{b c_{e}(2 \lambda+1)}{1+\lambda}}$ can we get the ideal maximum profit of the manufacturer. We have $\frac{\partial \pi_{m 4}}{\partial e}=0$ and get the optimal environmental quality of green products for manufacturers $e_{4}=$ $\frac{a(\lambda+1)(\tau+b \beta)}{4 b c_{e}(2 \lambda+1)-(\lambda+1)(\tau+b \beta)^{2}}$.

We finally get

$$
w_{4}=\frac{2 a c_{e}(\lambda+1)}{4 b c_{e}(2 \lambda+1)-(\lambda+1)(\tau+b \beta)^{2}} ; p 4=\frac{3 a c_{e}(\lambda+1)}{4 b c_{e}(2 \lambda+1)-(\lambda+1)(\tau+b \beta)^{2}} .
$$

\section{Proof of Proposition 9.}

With F-type government subsidies and retailer's fairness concern, we get that

$$
\begin{gathered}
\frac{\partial e_{4}}{\partial \tau}=\frac{a(\lambda+1)\left[4 b c_{e}(2 \lambda+1)+(\tau+b \beta)^{2}(\lambda+1)\right]}{\left[4 b c_{e}(2 \lambda+1)-(\tau+b \beta)^{2}(\lambda+1)\right]^{2}}>0 \\
\frac{\partial w_{4}}{\partial \tau}=\frac{4 a c_{e} \tau(\lambda+1)^{2}(\tau+b \beta)}{\left[4 b c_{e}(2 \lambda+1)-(\tau+b \beta)^{2}(\lambda+1)\right]^{2}}>0 \\
\frac{\partial p_{4}}{\partial \tau}=\frac{6 a c_{e}(\tau+b \beta)\left(2 \lambda^{2}+3 \lambda+1\right)}{\left[4 b c_{e}(2 \lambda+1)-(\tau+b \beta)^{2}(\lambda+1)\right]^{2}}>0 \\
\frac{\partial \pi_{m 4}}{\partial \tau}=\frac{a^{2} c_{e}(\tau+b \beta)(\lambda+1)^{2}}{\left[4 b c_{e}(2 \lambda+1)-(\tau+b \beta)^{2}(\lambda+1)\right]^{2}}>0 \\
\frac{\partial \pi_{r 4}}{\partial \tau}=\frac{4 a^{2} b c_{e}^{2}(\tau+b \beta)\left(8 \lambda^{3}+14 \lambda^{2}+7 \lambda+1\right)}{\left[4 b c_{e}(2 \lambda+1)-(\tau+b \beta)^{2}(\lambda+1)\right]^{3}}>0
\end{gathered}
$$

\section{Proof of Proposition 10.}

With F-type government subsidies and retailer's fairness concern, we get that

$$
\begin{gathered}
\frac{\partial e_{4}}{\partial \lambda}=\frac{-4 a b c_{e}(\tau+b \beta)}{\left[4 b c_{e}(2 \lambda+1)-(\tau+b \beta)^{2}(\lambda+1)\right]^{2}}<0 \\
\frac{\partial w_{4}}{\partial \lambda}=\frac{-8 a b c_{e}^{2}}{\left[4 b c_{e}(2 \lambda+1)-(\tau+b \beta)^{2}(\lambda+1)\right]^{2}}<0 \\
\frac{\partial p_{4}}{\partial \lambda}=\frac{-3 a c_{e}(\tau+b \beta)^{2}}{\left[4 b c_{e}(2 \lambda+1)-(\tau+b \beta)^{2}(\lambda+1)\right]^{2}}<0 \\
\frac{\partial \pi_{m 4}}{\partial \lambda}=\frac{-2 a^{2} b c_{e}^{2}}{\left[4 b c_{e}(2 \lambda+1)-(\tau+b \beta)^{2}(\lambda+1)\right]^{2}}<0
\end{gathered}
$$




$$
\begin{aligned}
& \frac{\partial \pi_{r 4}}{\partial \lambda}=\frac{2 a^{2} b c_{e}^{2}\left[4 b c_{e}(2 \lambda+1)-(\tau+b \beta)^{2}(5 \lambda+2)\right]}{\left[4 b c_{e}(2 \lambda+1)-(\tau+b \beta)^{2}(\lambda+1)\right]^{3}}>0 \\
& \Rightarrow \lambda<\frac{4 b c_{e}-2(\tau+b \beta)^{2}}{5(\tau+b \beta)^{2}-8 b c_{e}} \\
& \frac{\partial \pi_{r 4}}{\partial \lambda}=\frac{2 a^{2} b c_{e}^{2}\left[4 b c_{e}(2 \lambda+1)-(\tau+b \beta)^{2}(5 \lambda+2)\right]}{\left[4 b c_{e}(2 \lambda+1)-(\tau+b \beta)^{2}(\lambda+1)\right]^{3}}<0 \\
& \Rightarrow \frac{4 b c_{e}-2(\tau+b \beta)^{2}}{5(\tau+b \beta)^{2}-8 b c_{e}}<\lambda<\frac{4 b c_{e}-(\tau+b \beta)^{2}}{(\tau+b \beta)^{2}-8 b c_{e}}
\end{aligned} .
$$

\section{Proof of Proposition 11.}

With F-type government subsidies and retailer's fairness concern, we get that

$$
\begin{gathered}
\frac{\partial e_{4}}{\partial \beta}=\frac{a b(\lambda+1)\left[4 b c_{e}(2 \lambda+1)+(\tau+b \beta)^{2}(\lambda+1)\right]}{\left[4 b c_{e}(2 \lambda+1)-\tau^{2}(\lambda+1)\right]^{2}}>0 ; \\
\frac{\partial w_{4}}{\partial \beta}=\frac{4 a b c_{e}(\lambda+1)^{2}(\tau+b \beta)}{\left[4 b c_{e}(2 \lambda+1)-\tau^{2}(\lambda+1)\right]^{2}}>0 ; \\
\frac{\partial p_{4}}{\partial \beta}=\frac{6 a b c_{e}(\lambda+1)(2 \lambda+1)(\tau+b \beta)}{\left[4 b c_{e}(2 \lambda+1)-\tau^{2}(\lambda+1)\right]^{2}}>0 ; \\
\frac{\partial \pi_{m 4}}{\partial \beta}=\frac{a^{2} b c_{e}(\tau+b \beta)(\lambda+1)^{2}}{\left[4 b c_{e}(2 \lambda+1)-\tau^{2}(\lambda+1)\right]^{2}}>0 \\
\frac{\partial \pi_{r 4}}{\partial \beta}=\frac{4 a^{2} b^{2} c_{e}{ }^{2}(\tau+b \beta)\left(8 \lambda^{3}+14 \lambda^{2}+7 \lambda+1\right)}{\left[4 b c_{e}(2 \lambda+1)-(\tau+b \beta)^{2}(\lambda+1)\right]^{3}}>0
\end{gathered}
$$

\section{References}

1. Chitra, K. In search of the green consumers: A perceptual study. J. Serv. Res. 2007, 7, 173-191.

2. Zhang, L.; Wang, J.; You, J. Consumer environmental awareness and channel coordination with two substitutable products. Eur. J. Oper. Res. 2015, 241, 63-73. [CrossRef]

3. Chen, C. Design for the environment: A quality-based model for green product development. Manag. Sci. 2001, 47, 250-263. [CrossRef]

4. Zhang, X.; Xu, X.; He, P. New Product Design Strategies with Subsidy Policies. J. Syst. Sci. Syst. Eng. 2012, 21, 356-371. [CrossRef]

5. Luo, Z.; Chen, X.; Wang, X. The role of co-opetition in low carbon manufacturing. Eur. J. Oper. Res. 2016, 253, 392-403. [CrossRef]

6. Cohen, M.C.; Lobel, R.; Perakis, G. The impact of demand uncertainty on consumer subsidies for green technology adoption. Manag. Sci. 2016, 62, 1235-1258. [CrossRef]

7. Diamond, D. The impact of government incentives for hybrid-electric vehicles: Evidence from US states. Energy Policy 2008, 37, 972-983. [CrossRef]

8. Lobel, R.; Perakis, G. Consumer Choice Model for Forecasting Demand And Designing Incentives for Solar Technology; Working Paper; Massachusetts Institute of Technology (MIT): Cambridge, MA, USA, 2011.

9. Clark, A.E.; Oswald, A.J. Satisfaction and comparison income. J. Public Econ. 2000, 61, 359-381. [CrossRef]

10. Dahl, G.B.; Løken, K.V.; Mogstad, M. Peer Effects in Program Participation. Soc. Sci. Electron. Publ. 2013, 104, 2049-2074.

11. Nie, T.; Du, S. Dual-fairness supply chain with quantity discount contracts. Eur. J. Oper. Res. 2017, 258, 491-500. [CrossRef]

12. Du, S.; Du, C.; Liang, L.; Liu, T.Z. Supply chain coordination considering fairness concerns. J. Manag. Sci. China 2010, 13, 41-48. 
13. Zhou, W.; Huang, W. Contract designs for energy-saving product development in a monopoly. Eur. J. Oper. Res. 2016, 250, 902-913. [CrossRef]

14. Qiu, G. Influence of Fairness Concern on Decision-making of Manufacturers and Retailers under the Background of Government's Subsidy. J. Nanchang Hangkong Univ. (Soc. Sci.) 2013, 1, 45-52.

15. Amacher, G.S.; Koskela, E.; Ollikainen, M. Environmental quality competition and eco-labeling. J. Environ. Econ. Manag. 2004, 47, 284-306. [CrossRef]

16. Liu, Z.; Anderson, T.D.; Cruz, J.M. Consumer environmental awareness and competition in two-stage supply chains. Eur. J. Oper. Res. 2012, 218, 602-613. [CrossRef]

17. Xu, L.; Wang, C. Sustainable manufacturing in a closed-loop supply chain considering emission reduction and remanufacturing. Resour. Conserv. Recycl. 2018, 131, 297-304. [CrossRef]

18. Bansal, S.; Gangopadhyay, S. Tax/subsidy policies in the presence of environmentally aware consumers. J. Environ. Econ. Manag. 2003, 45, 333-355. [CrossRef]

19. Yu, Y.; Han, X.; Hu, G. Optimal production for manufacturers considering consumer environmental awareness and green subsidies. Int. J. Prod. Econ. 2016, 182, 397-408. [CrossRef]

20. Liu, D.; Wang, S.K.; Liu, J.C. Optimum Subsidy to Promote Electric Boiler Investment to Accommodate Wind Power. Sustainability 2017, 9, 874. [CrossRef]

21. Zheng, X.; Lin, H.; Liu, Z. Manufacturing Decisions and Government Subsidies for Electric Vehicles in China: A Maximal Social Welfare Perspective. Sustainability 2018, 10, 672. [CrossRef]

22. Oestreich, A.M.; Tsiakas, I. Carbon emissions and stock returns: Evidence from the EU Emissions Trading Scheme. J. Bank. Financ. 2015, 58, 294-308. [CrossRef]

23. Martin, R.; Wagner, U.; Muuls, M. The Impact of the European Union Emissions Trading Scheme on Regulated Firms: What Is the Evidence after Ten Years? Review of Environmental Economics and Policy. 2016, 10, 129-148. [CrossRef]

24. Liu, Q.; Zhang, C.; Bing, N.; Zhou, Y.; Shi, P. Supply chain two part Tariff Contract with Fairness Preference and Carbon Emissions. Chin. J. Manag. Sci. 2016, 10, 60-68.

25. Zhang, L.; Wang, J. Coordination of the Traditional and the Online Channels for a Short-life-cycle Product. Eur. J. Oper. Res. 2016, 258, 639-651. [CrossRef]

26. Sun, J.; Xiao, Z. The impact of government portfolio regulation on dual channel low carbon supply chain decision making. East China Econ. Manag. 2017, 9, 180-184.

27. Fehr, E.; Schmidt, K.M. A theory of fairness, competition, and cooperation. Q. J. Econ. 1999, 114, 817-868. [CrossRef]

28. Cui, T.H.; Raju, J.S.; Zhang, Z.J. Fairness and channel coordination. Manag. Sci. 2007, 53, $1303-1314$. [CrossRef]

29. Caliskan-Demirag, O.; Chen, Y.F.; Li, J. Channel coordination under fairness concerns and nonlinear demand. Eur. J. Oper. Res. 2010, 207, 1321-1326. [CrossRef]

30. Du, S.; Nie, T.; Chu, C.; Yu, Y. Newsvendor model for a dyadic supply chain with Nash bargaining fairness concerns. Int. J. Prod. Res. 2014, 52, 5070-5085. [CrossRef]

31. Chen, J.; Zhao, X.; Shen, Z.J. Risk Mitigation Benefit from Backup Suppliers in the Presence of the Horizontal Fairness Concern. Decis. Sci. 2015, 46, 663-696. [CrossRef]

32. Li, Q.H.; Li, B. Dual-channel supply chain equilibrium problems regarding retail services and fairness concerns. Appl. Math. Model. 2016, 40, 7349-7367. [CrossRef]

33. Jiang, H.; Shao, X.; Zhang, X.; Bao, J. A Study of the Allocation of Carbon Emission Permits among the Provinces of China Based on Fairness and Efficiency. Sustainability 2017, 9, 2122. [CrossRef]

34. Cheng, F.; Shao, S.; Xu, L.; Sun, L. Optimal Strategy of Government Subsidized Initiative Carbon Reduction. China Pop. Res. Environ. 2015, 7, 32-39.

35. Zhao, J.; Lin, J. Pricing models of closed-loop supply chain under different subsidy policies. J. Ind. Eng./Eng. Manag. 2017, 1, 85-92.

36. Carlson, D.K. Public Priorities: Environment vs. Economic Growth. 2005. Available online: http:/ / www.gallup.com/poll/15820/public-priorities-environmentvs-economic-growth.aspx (accessed on 12 April 2005). 
37. Laroche, M.; Bergeron, J.; Barbaro-Forleo, G. Targeting consumers who are willing to pay more for environmentally-friendly products. J. Consum. Mark. 2001, 18, 503-520. [CrossRef]

38. Zhu, W.; He, Y. Green product design in supply chains under competition. Eur. J. Oper. Res. 2017, 258, 165-180. [CrossRef] 